\title{
Endophytic Trichoderma Isolates from Tropical Environments Delay Disease Onset and Induce Resistance Against Phytophthora capsici in Hot Pepper Using Multiple Mechanisms
}

\author{
Hanhong Bae, ${ }^{1,2}$ Daniel P. Roberts, ${ }^{1}$ Hyoun-Sub Lim, ${ }^{1,3}$ Mary D. Strem, ${ }^{1}$ Soo-Chul Park, ${ }^{4}$ Choong-Min Ryu, ${ }^{5}$ \\ Rachel L. Melnick, ${ }^{1}$ and Bryan A. Bailey ${ }^{1}$ \\ ${ }^{1}$ U.S. Department of Agriculture, Agricultural Research Service, Beltsville Agricultural Research Center, Beltsville, MD 20705, \\ U.S.A.; ${ }^{2}$ School of Biotechnology, Yeungnam University, 214-1 Daedong, Gyeongsan-si, Gyeongbuk-do 712-749, Korea; \\ ${ }^{3}$ Department of Applied Biology, Chungnam National University, Daejeon, 305-764, Korea; ${ }^{4}$ Molecular \\ Genetics Division, National Institute of Agricultural Science and Technology, RDA, Suweon 441-707, Korea; ${ }^{5}$ Systems \\ Microbiology Research Center, Korea Research Institute of Bioscience and Biotechnology, Daejeon 305-600, Korea
}

Submitted 29 September 2010. Accepted 17 November 2010.

Endophytic Trichoderma isolates collected in tropical environments were evaluated for biocontrol activity against Phytophthora capsici in hot pepper (Capsicum annuum). Six isolates were tested for parasitic and antimicrobial activity against $P$. capsici and for endophytic and induced resistance capabilities in pepper. Isolates DIS 70a, DIS $219 \mathrm{~b}$, and DIS $376 \mathrm{f}$ were $P$. capsici parasites, while DIS 70a, DIS 259j, DIS 320c, and DIS 376f metabolites inhibited $P$. capsici. All six isolates colonized roots but were inefficient stem colonizers. DIS 259j, DIS 320c, and DIS 376f induced defense-related expressed sequence tags (EST) in 32-day-old peppers. DIS 70a, DIS 259j, and DIS 376f delayed disease development. Initial colonization of roots by DIS 259j or DIS 376f induced EST with potential to impact Trichoderma endophytic colonization and disease development, including multiple lipid transferase protein (LTP)like family members. The timing and intensity of induction varied between isolates. Expression of CaLTP-N, encoding a LTP-like protein in pepper, in $N$. benthamiana leaves reduced disease development in response to $P$. nicotianae inoculation, suggesting LTP are functional components of resistance induced by Trichoderma species. Trichoderma isolates were endophytic on pepper roots in which, depending on the isolate, they delayed disease development by $P$. capsici and induced strong and divergent defense reactions.

Current address for Hanhong Bae: School of Biotechnology, Yeungnam University, 214-1 Daedong, Gyeongsan-si, Gyeongbuk-do 712-749, Korea.

Current address for Hyun-Sub Lim: Department of Applied Biology, Chungnam National Univ., Daejeon, 305-764, Korea.

Corresponding author: B. A. Bailey; E-mail: bryan.bailey@ars.usda.gov

*The $e$-Xtra logo stands for "electronic extra" and indicates that two supplementary tables and supplementary results information are published online. Figure 1 also appears in color online.

This article is in the public domain and not copyrightable. It may be freely reprinted with customary crediting of the source. The American Phytopathological Society, 2011.
Genus Trichoderma species have been described as "opportunistic avirulent plant symbionts" due to their abilities to benefit from and provide benefit in direct interactions with plants (Harman et al. 2004). Most of this discussion centered on Trichoderma spp. as soil inhabitants and root colonizers. The biocontrol capabilities of several Trichoderma species have been extensively documented (Harman et al. 2004). Trichoderma isolates employ several mechanisms in providing biocontrol of disease, including antibiosis, parasitism, and induced resistance. In the context of Trichoderma species limiting disease, antibiosis results from the production of antimicrobial metabolites by Trichoderma spp. (Harman et al. 2004; Howell 1998, 2003), while parasitism is evidenced by the direct penetration and parasitism of pathogens by Trichoderma spp. (Chet et al. 1998; Harman et al. 2004). Induced resistance results when plant defense is activated in response to Trichoderma colonization (Alfano et al. 2007; Djonovic et al. 2006; Harman et al. 2004; Korolev et al. 2007; Meyer et al. 1998; Segarra et al. 2009; Shoresh and Harman 2008a; Shoresh et al. 2005). A Trichoderma isolate may use more than one of these mechanisms in providing biocontrol of plant diseases.

We have been studying a group of Trichoderma isolates collected from highly competitive tropical environments (Bailey et al. 2006, 2008). They are unique because they were isolated as endophytes not of roots but of aerial plant tissues, including tree trunks, stems, and fruit (Bailey et al. 2006, 2008). In developing this collection, many new Trichoderma species have been described. Examples include T. ovalisporum (Holmes et al. 2004), T. martiale (Hanada et al. 2008), T. stromaticum (Samuels et al. 2000), T. theobromicola, and T. paucisporum (Samuels et al. 2006b), T. koningiopsis (Samuels et al. 2006a), and T. evansii (Samuels and Ismaiel 2009). The biocontrol potentials of these newly described species are being studied, but details on their activities are lacking. Primarily, they have been studied in the tropical crop Theobroma cacao (Bailey et al. 2006; Hanada et al. 2008; Holmes et al. 2004; Samuels et al. 2000).

Although collected from plants in tropical climates, we see no a priori reason why the biocontrol potential of these Trichoderma isolates should be limited to tropical cropping systems. Specificity may exist between microbes and their host plants through coevolution (Burdon and Thrall 2009). The possibility that plant host specificity has contributed to the development 
of new Trichoderma species capable of colonizing plant canopies in a tropical environment is intriguing but yet unproven.

One of the diseases being targeted for biocontrol in cacao is black pod, caused by several Phytophthora species including $P$. capsici, $P$. citrophthora, $P$. palmivora, and $P$. megakarya (Guest 2007). Phytophthora species cause disease in many different plant species (Birch et al. 2006). P. capsici has a broad host range but isolates can show specificity (Tian and Babadoost 2004). For example, although some isolates of $P$. capsici cause disease on cacao, others cause a devastating disease on hot pepper (Capsicum annuum), causing severe yield losses (Kim and Hwang 1992).

In this study, the first objective was to determine if Trichoderma isolates collected as endophytes of plants in tropical climates can establish endophytic relationships with hot pepper and can provide control of disease in the $P$. capsici-pepper pathosystem. The second objective was to characterize the different biocontrol activities possessed by the Trichoderma isolates and the consequences of their endophytic associations with pepper. The third objective was to determine whether transient expression of Trichoderma-induced pepper expressed sequence tags (EST) related to resistance could reduce disease development in $N$. benthamiana leaves infected by $P$. nicotianae.

\section{RESULTS}

\section{Parasitism.}

The six Trichoderma isolates (Table 1) were evaluated for their abilities to parasitize $P$. capsici mycelia. Five of the six isolates (all but DIS 320c) completely colonized the $P$. capsici precolonized plates within 7 days (Table 2). Only three of the isolates, DIS 70a, DIS 219b, and DIS 376f, prevented P. capsici from being reisolated from the $P$. capsici side of the precolonized plates (Table 2). P. capsici was not reisolated, while DIS 320c was reisolated. Water agar slides were coinoculated with $P$. capsici and individual Trichoderma isolates. Intense coiling of DIS $259 \mathrm{j}$ mycelia on and around the P. capsici mycelia was observed but without penetration (Fig. 1H). DIS 70a (Fig. 1F) and DIS $376 \mathrm{f}$ (Fig. 1E) directly penetrated the P. capsici mycelia but without significant coiling. DIS 219b (Fig. 1C) and DIS 85f (Fig. 1G) were observed to form parallel associations with $P$. capsici mycelia, but penetration was not observed. DIS 320c repressed normal growth of $P$. capsici, resulting in densely stained mycelium tips (Fig. 1D), but neither coiling nor penetration was observed.

\section{Antibiosis and phytotoxicity.}

Extracellular metabolites were harvested from Trichoderma culture filtrates and were evaluated for their antibiosis activities against $P$. capsici and their phytotoxic activities against pepper. In the antibiosis study, DIS 320c completely prevented growth of $P$. capsici (Table 2). DIS 259j, DIS 70a, and DIS $376 \mathrm{f}$ produced metabolites that inhibited growth of $P$. capsici $56.5,30.7$, and $19.2 \%$, respectively (Table 2). Metabolites produced by DIS 320c also damaged pepper roots, causing the tips to brown (data not shown). The metabolites produced by the other isolates did not damage pepper roots.

Trichoderma endophytic growth in hot pepper.

The six Trichoderma isolates (Table 1), DIS 70A, DIS 85f, DIS 219b, DIS 259j, DIS 320c, and DIS 376f, were 100\% effi-

Table 1. Trichoderma isolates used, their species, host plant, country of origin, and reference to isolate or species description

\begin{tabular}{lllll}
\hline Isolate & Species & Host & Origin & Reference \\
\hline DIS 70a & T. ovalisporum & Banisteriopsis caapi & Ecuador & Holmes et al. 2004 \\
DIS 85f & T. theobromicola & Theobroma cacao & Peru & Samuels et al. 2006b \\
DIS 219b & T. hamatum & Theobroma gileri & Ecuador & Bae at al. 2009 \\
DIS 259j & T. stilbohypoxyli & Theobroma cacao & Ecuador & Lu and Samuels 2003 \\
DIS 320c & T. caribbaeum var. aequatoriale & Theobroma gileri & Ecuador & Samuels et al. 2006a \\
DIS 376f & T. theobromicola & Cola praecuta & Camaroon & Samuels and Ismaiel 2009 \\
\hline
\end{tabular}

${ }^{\mathrm{z}}$ Isolate DIS $259 \mathrm{j}$ has only recently been described. All of the strains were provided by G. J. Samuels, who identified them by sequencing a 0.65 -kb region of the translation-elongation factor 1-alpha (tef1) gene. The GenBank number for isolate DIS 259j tef1 is GQ862819.

Table 2. Endophytic growth, parasitism, and antibiosis activities of six selected endophytic Trichoderma isolates ${ }^{\mathrm{w}}$

\begin{tabular}{|c|c|c|c|c|c|c|c|c|}
\hline \multirow[b]{3}{*}{ Isolate } & & & \multicolumn{4}{|c|}{ Viable biomass $^{y}$} & & \\
\hline & \multicolumn{2}{|c|}{ Endophytic growth ${ }^{x}$} & \multicolumn{2}{|c|}{ Phytophthora capsici side } & \multicolumn{2}{|c|}{ Trichoderma side } & \multicolumn{2}{|c|}{ Growth inhibition $^{z}$} \\
\hline & Root & Stem & $\mathbf{T}$ & $\mathbf{P}$ & $\mathbf{T}$ & $\mathbf{P}$ & Colony diameter & Inhibition \\
\hline Control & 0 & 0 & - & 100 & - & 100 & $2.6 \pm 0.04$ & 0 \\
\hline DIS 70a & 100 & 4.2 & 100 & 0 & 100 & 0 & $1.80 \pm 0.04$ & 30.7 \\
\hline DIS $85 f$ & 100 & 4.2 & 100 & 100 & 100 & 100 & $3.08 \pm 0.04$ & -18.5 \\
\hline DIS 219b & 100 & 0 & 100 & 0 & 100 & 0 & $3.65 \pm 0.06$ & -40.4 \\
\hline DIS $259 \mathrm{j}$ & 100 & 11.1 & 100 & 100 & 100 & 100 & $1.13 \pm 0.05$ & 56.5 \\
\hline DIS 320c & 100 & 6.9 & 33 & 67 & 100 & 0 & 0 & 100 \\
\hline DIS $376 f$ & 100 & 1.4 & 100 & 0 & 100 & 0 & $2.10 \pm 0.07$ & 19.2 \\
\hline
\end{tabular}

${ }^{\mathrm{w}}$ Endophytic growth was determined by the ability of Trichoderma isolates to internally colonize pepper roots or stems and survive surface sterilization Parasitism was determined by the ability of Trichoderma isolates to colonize P. capsici precolonized plates from the Trichoderma-inoculated side to the opposite edge where the $P$. capsici was originally inoculated and to prevent $P$. capsici regrowth from subsamples. Antibiosis was determined by the ability of Trichoderma metabolites from culture filtrate to inhibit growth of $P$. capsici when incorporated into agar media.

x Seedlings grown for 35 days in Trichoderma-precolonized soil were dissected and surface-sterilized, and approximately 1-cm of surface-sterilized tissue sections of roots and stems were plated on cornmeal dextrose agar. For each seedling, four lower stem sections and one root section were plated and were observed for Trichoderma growth (percentage of sections showing growth).

${ }^{\text {y }}$ At 7 days after inoculation of $P$. capsici-precolonized plates with Trichoderma isolates, agar plugs were removed from the $P$. capsici- and Trichodermainoculated sides. Each plug was plated and observed for growth of Trichoderma $(\mathrm{T})$ or P. capsici (P). Data are presented as percentage of plugs showing growth of $P$. capsici or Trichoderma.

${ }^{\text {z }}$ A 5-mm-diameter plug of $P$. capsici R198 was added to agar plates containing heat-treated Trichoderma culture filtrates in minimal salts broth agar media. The mean radial growth of $P$. capsici was observed after 5 days of incubation. Data are presented as colony diameter \pm standard error and percent inhibition of growth relative to growth on control plates. 

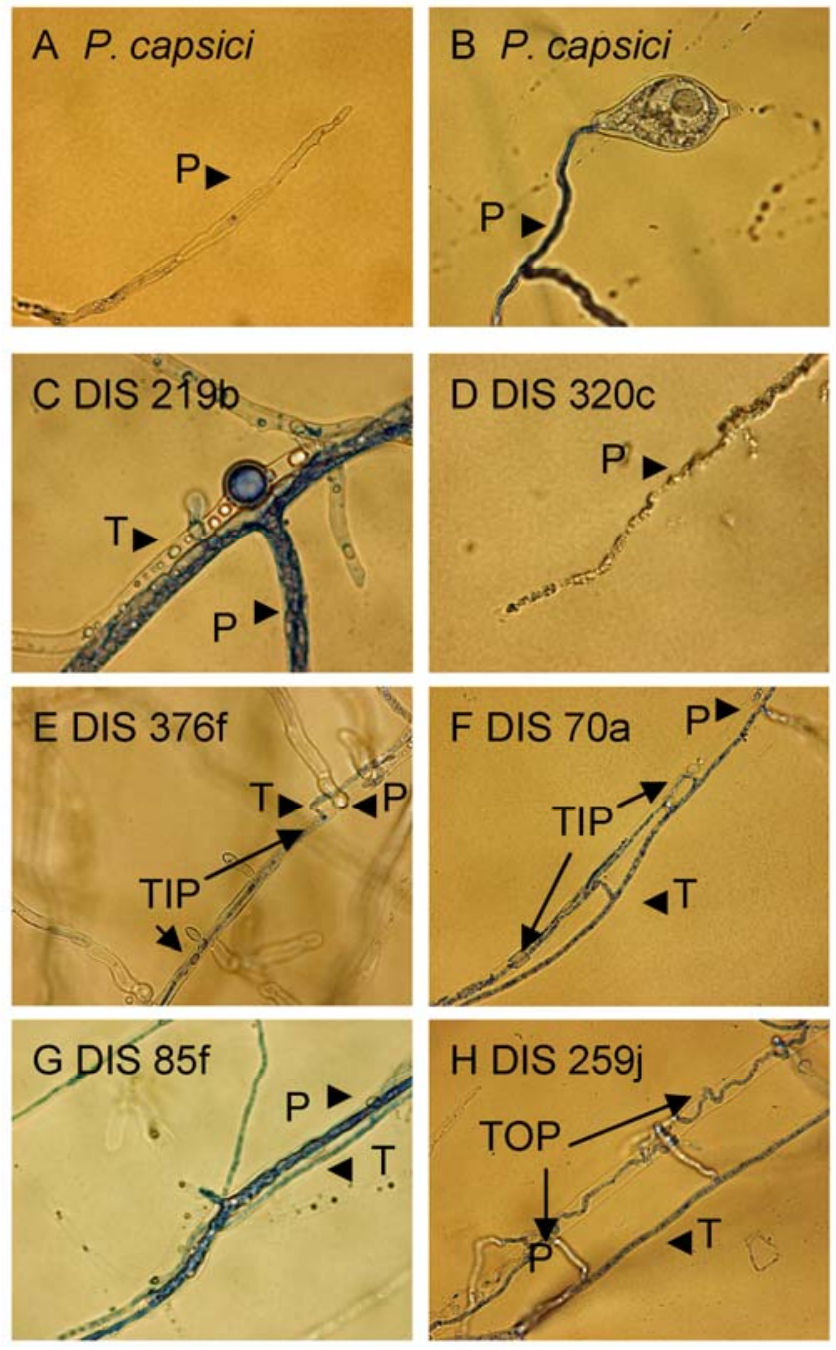

Fig. 1. Interactions between Trichoderma isolates and Phytophthora capsici on water agar slides. Glass slides covered with water agar were inoculated at opposite ends with agar plugs of $P$. capsici R198 and individual Trichoderma isolates. After 5 days of incubation, the slides were stained with lacto phenol cotton blue and were observed under the microscope (600× magnification) in areas at which the Trichoderma isolates had overgrown the $P$. capsici. A, $P$. capsici mycelium, B, $P$. capsici germinating sporangia, $P$. capsici in the presence of Trichoderma, C, DIS 219b, D, DIS 320c, E, DIS 376f, F, DIS 70a, G, DIS 85f, H, DIS 259j. P $=P$. capsici, $\mathrm{T}=$ Trichoderma, $\mathrm{TIP}=$ Trichoderma mycelium in Phytophthora mycelium, TOP = Trichoderma mycelium on Phytophthora mycelium. The size bar for the figure $(\mathrm{H})$ represents $16.7 \mu \mathrm{m}$. cient in colonizing pepper roots (Table 2). In contrast, the maximum endophytic colonization of pepper stems by any isolate was $11.1 \%$.

\section{Late-stage systemic induced resistance.}

Depending on the isolate, Trichoderma colonization altered expression of candidate stress responsive genes and EST in 32day-old pepper seedlings. Data for 12 genes and EST (Table 3) are presented for roots (Fig. 2) and leaves (Fig. 3). Genes CaLTP1, CaCH21, CaPO1, CaPR4, CaSC1, and CaPEAS1 showed altered expression in pepper roots 32 days after Trichoderma colonization in an isolate-dependent manner (Fig. 2). DIS 259j, DIS 320c, and DIS 376f were the most consistent inducers of gene and EST expression in root. Inoculation of pepper roots with Trichoderma spp. altered the expression of genes and EST in leaves encoding pathogenesis-related (PR) proteins (CaLTP1, CaPRl, CaCHI2, CaPR4), enzymes involved in secondary metabolism (CaSC1, CaHMG2), hormone biosynthesis or action (CaJA2, CaNPR1, CaGA2ox), and gene regulation (CaMAPK4, CaMK1). The Trichoderma isolates altering gene and EST expression in leaves most consistently were DIS 259j, DIS 320c, and DIS 376f (Fig. 3).

\section{Biocontrol of disease.}

Pepper seedlings (42-day-old) precolonized by individual Trichoderma isolates were transplanted into $P$. capsici-infested soil and were observed for disease symptom development for 14 days (Fig. 4). Symptoms typically were expressed as a rapidly expanding black lesion at the stem base, emanating from below the soil line, followed by wilting within $24 \mathrm{~h}$. The most consistent isolate in delaying symptom expression was DIS 376f, which delayed symptom expression by more than three days when averaged over the three independent disease assays (Table 4). At the end of the three disease assays (Fig. 4), 50, 60, and $25 \%$ of the pepper seedlings precolonized by DIS $376 \mathrm{f}$ remained asymptomatic while 0,10 , and $0 \%$ of control plants remained asymptomatic. DIS 259j and DIS 70a were next in efficiency at delaying symptom expression when considered over all three disease assays (Table 4).

\section{Early induced responses}

to Trichoderma colonization in hot pepper.

In order to study the early interactions between the Trichoderma spp. and hot pepper, seedlings were grown on artificial media for 14 days and were then inoculated with individual Trichoderma isolates. Initially, a study was carried out using all six Trichoderma isolates and 24-day-old seedlings. The roots were harvested after $72 \mathrm{~h}$ of exposure to Trichoderma

Table 3. Pepper genes and expressed sequence tags (EST) used in evaluating the response of pepper seedlings to Trichoderma colonization

\begin{tabular}{|c|c|c|c|}
\hline EST & Putative function & GenBank ID & Citation \\
\hline CaAct & Actin & AY572427 & \\
\hline CaPR1 & Pathogenesis related (PR1) & AF053343 & Kim and Hwang 2000 \\
\hline CaLTP1 & Lipid tranferase-like protein (LTP)-like (LTPI/PR2) & AF208832 & Jung et al. 2003 \\
\hline CaPR4 & Pathogenesis-related (PR4) & AF244122 & Shin et al. 2001 \\
\hline CaPR5 & Pathogenesis-related (PR5) & AY262059 & \\
\hline $\mathrm{CaCHI} 2$ & Chitinase class II & AF091235 & Hong et al. 2000 \\
\hline CaNPR1 & NPR1 & DQ648785 & \\
\hline CaJA2 & JA2 & GD080747.1 & \\
\hline CaMAPK4 & MAPK4 & BM064802.1 & \\
\hline CaSC1 & Sesquiterpene cyclase & AF061285 & Back et al. 1998 \\
\hline CaHMG2 & 3-hydroxy-3-methyl-glutaryl-coenzyme A reductase & AF110383 & Ha et al. 2003 \\
\hline $\mathrm{CaPO1}$ & Peroxidase (PO1) & AF442386 & Do et al. 2003 \\
\hline $\mathrm{CaPO} 2$ & Cell wall peroxidase & DQ489711 & Choi et al. 2007 \\
\hline CaPEAS1 & 5-Epi-aristolochene & AJ005588 & Zavala-Paramo et al. 2000 \\
\hline CaPR10 & Pathogenesis-related (PR10) & AF44121 & Shin et al. 2001 \\
\hline CaGA2ox & Gibberellic acid 2-oxidase & DQ465393 & \\
\hline CaMK1 & Mitogen-activated protein kinase 1 (MK1) & AF247135 & Shin et al. 2001 \\
\hline
\end{tabular}


spp., and gene and EST expression was evaluated by quantitative polymerase chain reaction (qPCR). In these same samples, expression of the Trichoderma actin gene (TriACT) was determined. The data are presented in two ways: i) for fungal actin (TriACT) and hot pepper genes and EST, EST expression as a percent of hot pepper actin expression, and ii) for hot pepper genes and EST, the fold increase in EST expression relative to TriACT expression ( $\mathrm{FI}_{/ \% \text { Tact }}$ ) as described below. All six Trichoderma isolates altered expression of one or more pepper genes and EST relative to plant actin expression, but the strongest inducers were DIS 219b and DIS 259j (Fig. 5, left panel).
When pepper gene and EST fold induction is calculated in terms relative to TriACT expression, which proposes Trichoderma colonization, a different picture emerges. DIS 85f, DIS 259j, and DIS 376f were stronger inducers of pepper gene expression when the level of Trichoderma colonization was considered (Fig. 5, right panel). The expression levels for TriACT were $12.2,2.7,15.9,1.5,7.1$, and $4.4 \%$ of pepper actin (CaACT) expression for DIS 70a, DIS 85f, DIS 219b, DIS 259j, DIS 320c, and DIS 376f, respectively. Based on the expression level of TriACT in root tissues $72 \mathrm{~h}$ after Trichoderma inoculation, DIS 219b and DIS 70a heavily colonized pepper

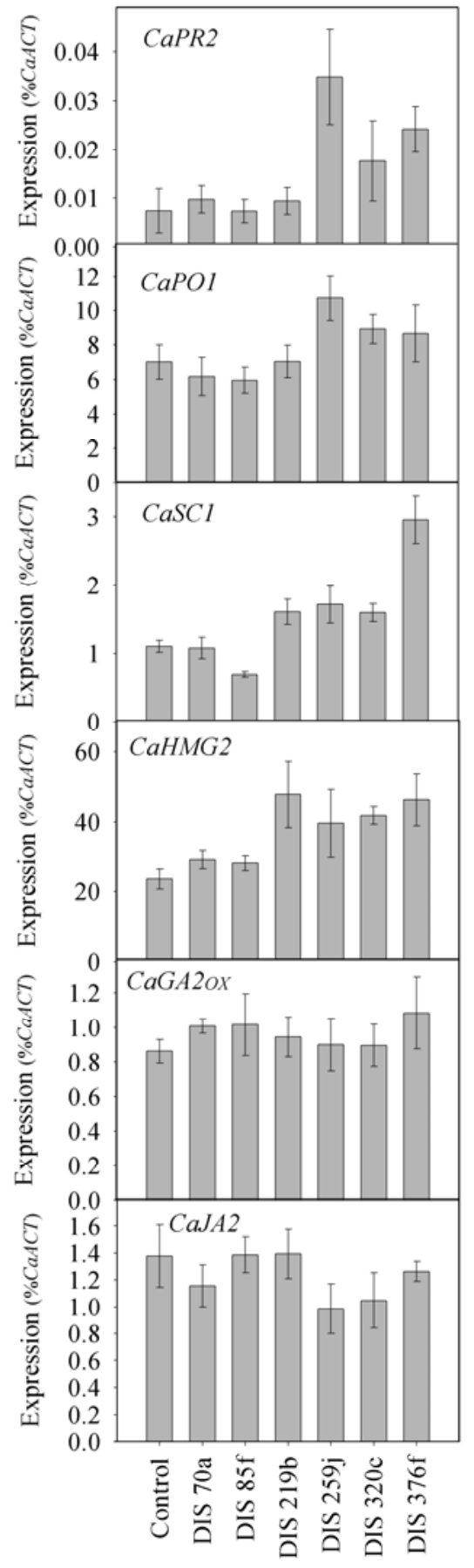

Isolate

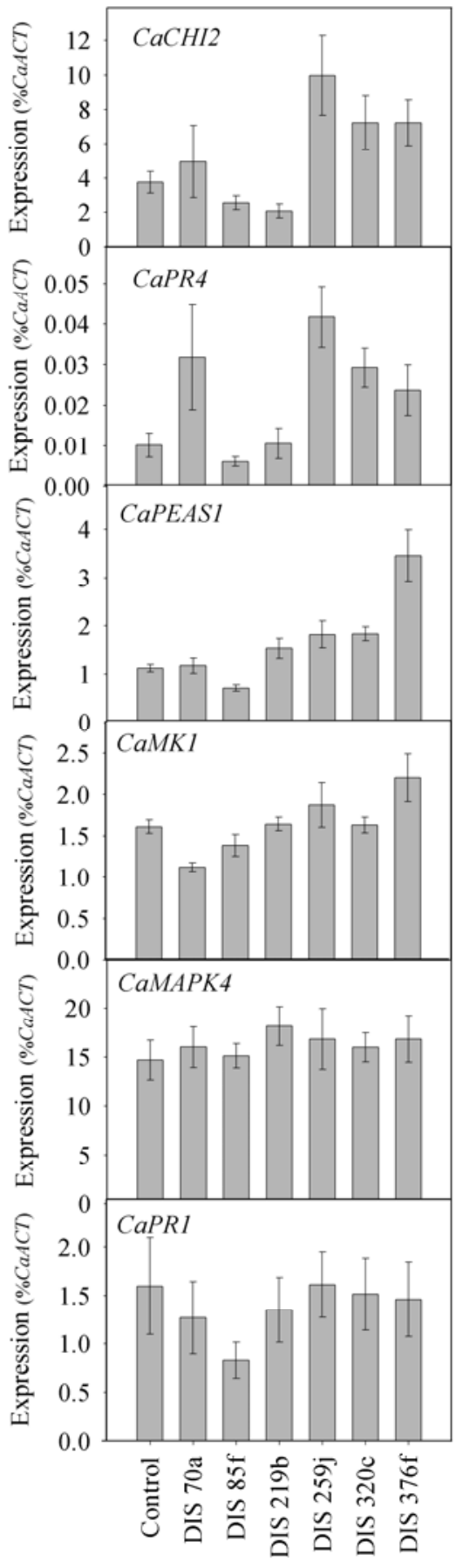

Isolate

Fig. 2. Gene expression in pepper roots 32 days after inoculation with Trichoderma isolates. Pepper seeds were planted in Pro-Mix PGX inoculated with Trichoderma isolates. Seedlings were grown in a controlled environment chamber with a 12-h-light and 12-h-dark photoperiod at $25^{\circ} \mathrm{C}$. After 32 days, roots were harvested for quantitative polymerase chain reaction. Genes and expressed sequence tags (Table 3) include CaLTP1, CaCHI2, CaPO1, CaPR4, CaSC1, CaPEAS1, CaHMG2, CaMK1, CaGA2ox, CaMAPK4, CaJA2, and CaPR1. 
roots followed by DIS 320c and DIS 376f, followed by DIS 85f, and then DIS 259j.

Microarray analysis using a single biological replication was carried out (Supplementary Results) to identify candidate EST for further analysis of DIS $259 \mathrm{j}$ - and DIS $376 \mathrm{f}$-induced samples by qPCR, using a 36- to 72-h timecourse fully replicated six times. The universal TriACT primer set (Supplementary Table S1) was used to assess the relative level of colonization of the pepper roots by DIS 259j and DIS $376 f$ (Fig. 6). Visual observations of plate colonization indicate the two Trichoderma isolates completely colonized the plates the pepper seedlings were growing on, with less than a 12-h difference between the two isolates (Fig. 6A). The levels of TriACT transcript detected for each isolate were different from levels detected in the control samples but were not different between isolates regardless of the time sampled (Fig. 6B).

The expression levels of 12 EST highly induced in the microarray results were analyzed (Table 5, Supplementary Table $\mathrm{S} 2$ for statistical analysis). EST CaAEC (an auxin efflux carrier component) was similarly induced by DIS $259 \mathrm{j}$ and DIS $376 \mathrm{f}$ at $48 \mathrm{~h}$, six EST were preferentially induced by DIS $259 \mathrm{j}$, and seven EST were preferentially induced by DIS 376f (Fig. 7). All 12 EST studied to verify the microarray were induced by one or both of the Trichoderma isolates during the time-

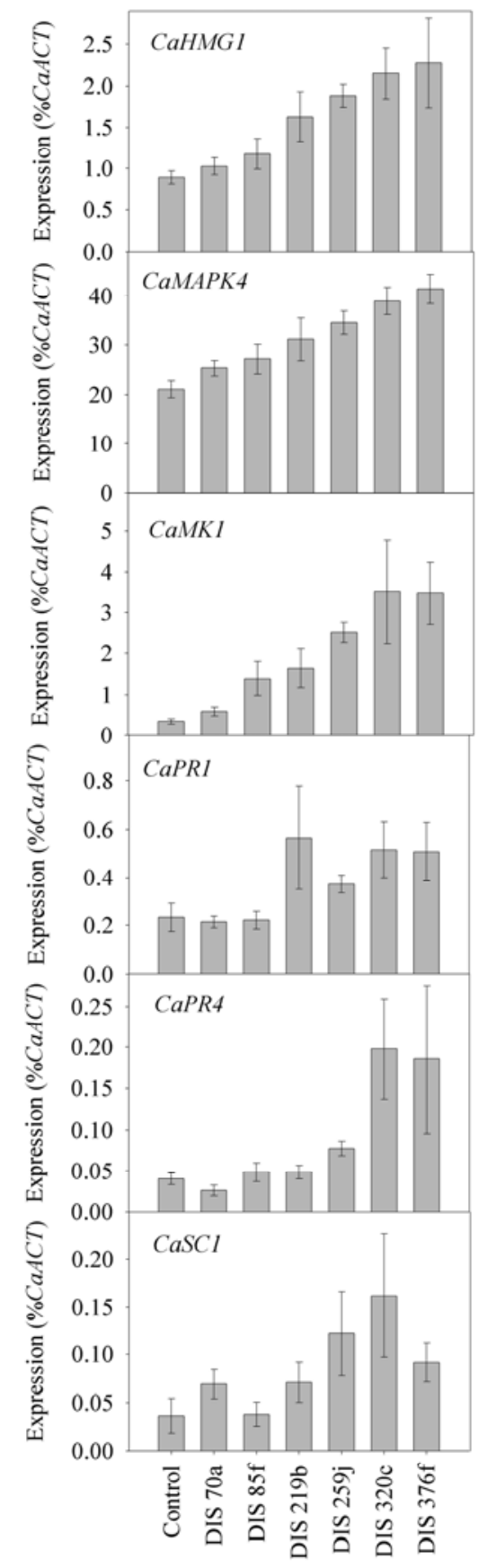

Isolate

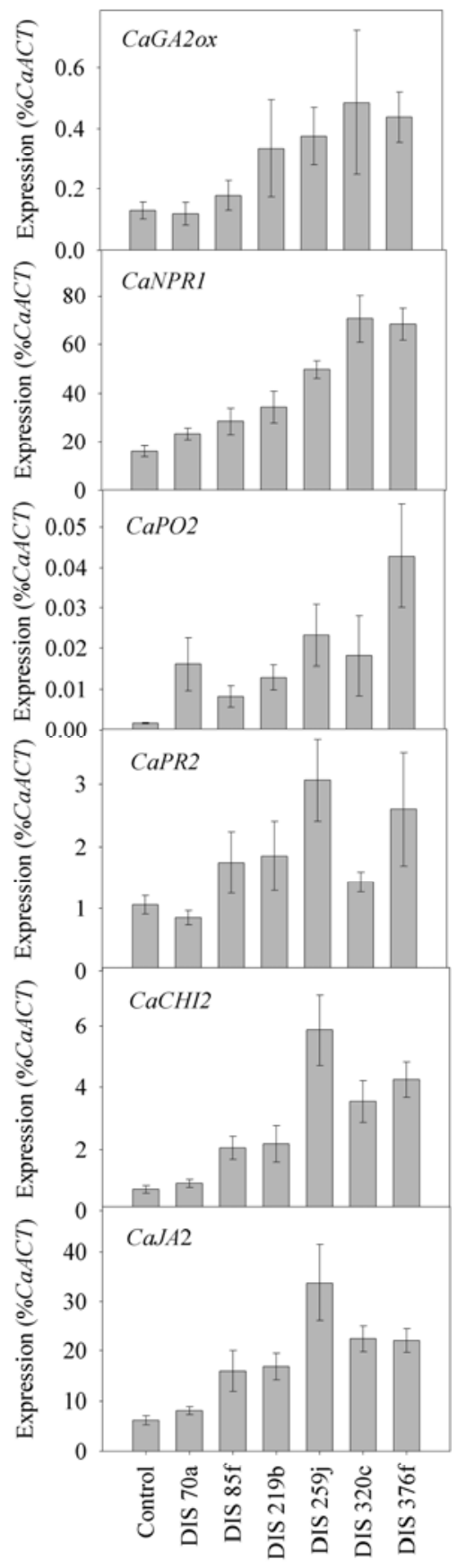

Isolate

Fig. 3. Gene expression in pepper leaves 32 days after inoculation with Trichoderma isolates. Pepper seeds were planted in Pro-Mix PGX mix inoculated with Trichoderma. Seedlings were grown in a controlled environment chamber with a 12-h-light and 12 -h-dark photoperiod at $25^{\circ} \mathrm{C}$. After 32 days, leaves above the fifth node were harvested for quantitative polymerase chain reaction. Gene/expressed sequence tags include $C a H M G 2$, CaGA2ox, CaMAPK4, CaNPR1, CaMK1, CaPO2, CaLTP1, CaPR1, CaCHI2, CaPR4, CaJA2, and CaSC1. 
course, and all 12 of the EST followed the pattern of isolatespecific induction at $48 \mathrm{~h}$ indicated by the microarray analysis. DIS 259j induced CaPOR (porin/voltage-dependent anion channels), CaPER (a peroxidase), CaTR (a tropinone reductase), $C a Z F P$ (zinc finger protein), and $C a B K C$ (beta-ketoacylCoA synthase/FIDDLEHEAD-like). DIS 376f induced CaMLO (seven transmembrane proteins), $\mathrm{CaCYP}$ (cytochrome P450), CaGT (1,6-glucosyltransferase), CaACS (1-aminocyclopropane-1-carboxylate [ACC] synthase), and CaGAD (glutamate decarboxylase).

An additional 12-member subset (Table 6) of lipid tranferase protein (LTP)-like family members was studied by qPCR analysis over the 36- to 72-h postinoculation timecourse (Fig. 8). The subset was assembled based on sequence similarity to Arabidopsis EST and differential expression in response to the
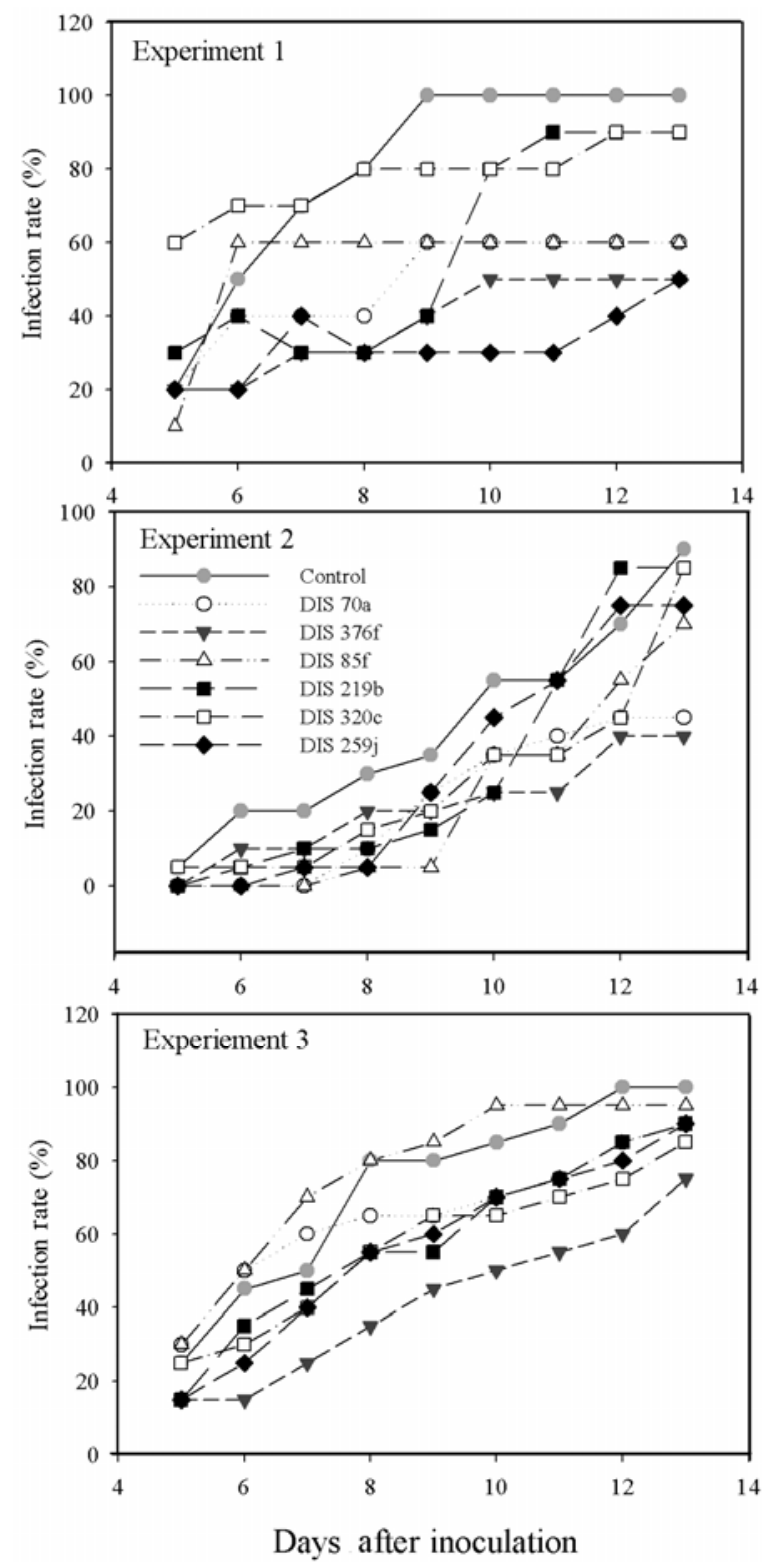

Fig. 4. Impact of Trichoderma spp. on disease development in pepper caused by Phytophthora capsici. Individual 42-day-old pepper plants (Trichoderma-inoculated or uninoculated controls) were transplanted into soil infested with $P$. capsici. Three experiments were carried out consisting of 10,20 , and 20 replicate pots per treatment, with one plant per pot, arranged in a completely randomized design. The percentage of diseased plants receiving each treatment was determined daily for 14 days after transplanting. two Trichoderma isolates in the microarray results. DIS $376 \mathrm{f}$ preferentially induced CaLTP-I, and CaLTP-L. DIS 259j preferentially induced $C a L T P-C, C a L T P-N, C a L T P-B, C a L T P-A$, CaLTP-J, and CaLTP-E. CaLTP-M, CaLTP-F, and CaLTP-K were induced by both DIS 259j and DIS 376f.

\section{Expressing Trichoderma-induced pepper genes in $N$. benthamiana leaves.}

Expression of CaLTP-N, CaPOR, and CaMLO 3 days after agroinfiltration of $N$. benthamiana leaves was detected at an average $3.7,6.2$, and $22.6 \%$ of $N$. benthamiana actin expression, respectively. The area under the disease progress curve (AUDPC) for leaves infiltrated with pGD-CaLTP-N was reduced by $42 \%$ in comparison with the pGD-empty vector control (Table 7). The results for the pGD-CaPOR and pGDCaMLO were inconsistent between experiments, even though their mean AUDPC were lower than the empty vector controls.

\section{DISCUSSION}

Isolates DIS 70a, DIS 219b, and DIS 376f completely eliminated $P$. capsici growth when cocultured. DIS 70a and DIS 376 f penetrated $P$. capsici without coiling. Coiling, a common recognition response of parasitic Trichoderma (Chet et al. 1998; Harman et al. 2004), is not a requirement for parasitism. DIS $70 \mathrm{a}$ is also a parasite of the basidiomycete Moniliophthora roreri, causal agent of frosty pod rot on Theobroma cacao, demonstrating a broad host range across kingdoms and plant hosts (Bailey et al. 2008). Trichoderma species produce many metabolites with antimicrobial activity (Howell 1998) and also produce metabolites that inhibit plant growth (Bailey and Lumsden 1998). DIS 320c produced metabolites that strongly inhibited growth of $P$. capsici. The DIS 320c metabolites inhibiting $P$. capsici growth may be related to the metabolites in those same samples, causing damage to pepper roots. Phytophthora species are globally spread and cause disease on many different plant species (Birch et al. 2006), including species from which some of the Trichoderma isolates were collected (Bowers et al. 2001; Guest 2007). The Trichoderma isolates have been exposed to many pathogenic and beneficial microbes during their evolution into unique species, and antibiosis and parasitism capabilities against Phytophthora and other plant pathogens may have proven advantageous.

Trichoderma isolates collected from aerial plant tissues in the tropics were inefficient colonizers of hot pepper stems, although they efficiently internally colonized hot pepper roots. Five of the isolates studied can be considered endophytes, since they penetrated and survived in pepper roots without causing observable damage (Stone et al. 2000). Isolate DIS320c is a

Table 4. Increase in the average number of days without symptoms (DWS) in response to Trichoderma treatment ${ }^{\mathrm{y}}$

\begin{tabular}{lcc}
\hline Treatment & DWS & Means separation \\
\hline Control & 7.2 & $\mathrm{C}^{\mathrm{Z}}$ \\
DIS 70a & 9.3 & $\mathrm{AB}$ \\
DIS 85f & 8.6 & $\mathrm{ABC}$ \\
DIS 219b & 8.7 & $\mathrm{ABC}$ \\
DIS 259j & 9.7 & $\mathrm{AB}$ \\
DIS 320c & 8.5 & $\mathrm{BC}$ \\
DIS 376f & 10.5 & $\mathrm{~A}$ \\
\hline
\end{tabular}

${ }^{\mathrm{y}}$ Three experiments were carried out. Trichoderma-colonized seedlings and controls were transplanted into Phytophthora capsici-infested soil and were monitored daily for symptom development for 14 days. Symptoms were sunken necrotic lesions on the stem at the soil line, followed by wilting of the plant. DWS values represent the average over three experiments. ${ }^{\mathrm{z}}$ Means not followed by the same letters are significantly different $(P \leq$ $0.05)$. 


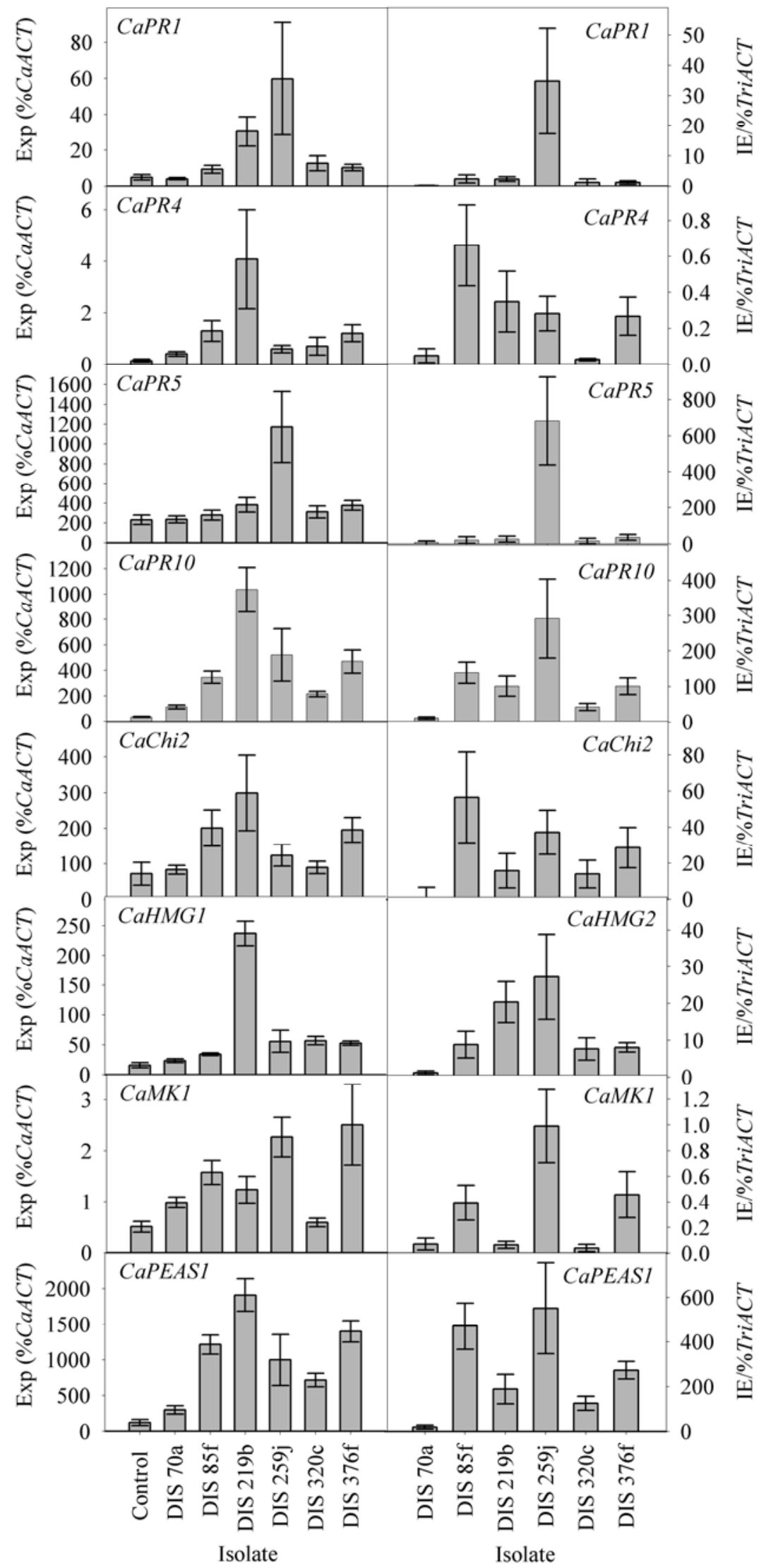

Fig. 5. The early response of pepper root gene expression after inoculation with Trichoderma isolates. Pepper seedlings were grown for 14 days and were inoculated with Trichoderma isolates on agar plates to determine the early responses in the pepper-Trichoderma interaction. Pepper roots were harvested $72 \mathrm{~h}$ after inoculation, and RNA was extracted for quantitative polymerase chain reaction analysis. The expression of eight pepper expressed sequence tags (EST) responsive to stress were analyzed, i.e., CaPR1, CaPR5, CaMK1, CaPEAS1, CaCHI2, CaPR10, CaPR4, and CaHMG2. The data are expressed as a percentage of pepper actin expression for each sample (graphs on the left) and the increase in EST expression (fold induction) relative to Trichoderma actin expression (graphs on the right). 
possible exception, since it produced compounds that damaged roots. The endophytic nature of two of the isolates, DIS 70a and DIS 219b, has been studied in detail on cacao (Bae et al. 2009; Bailey et al. 2006, 2008). They are aggressive endophytes of cacao, being reisolated at high frequencies from the
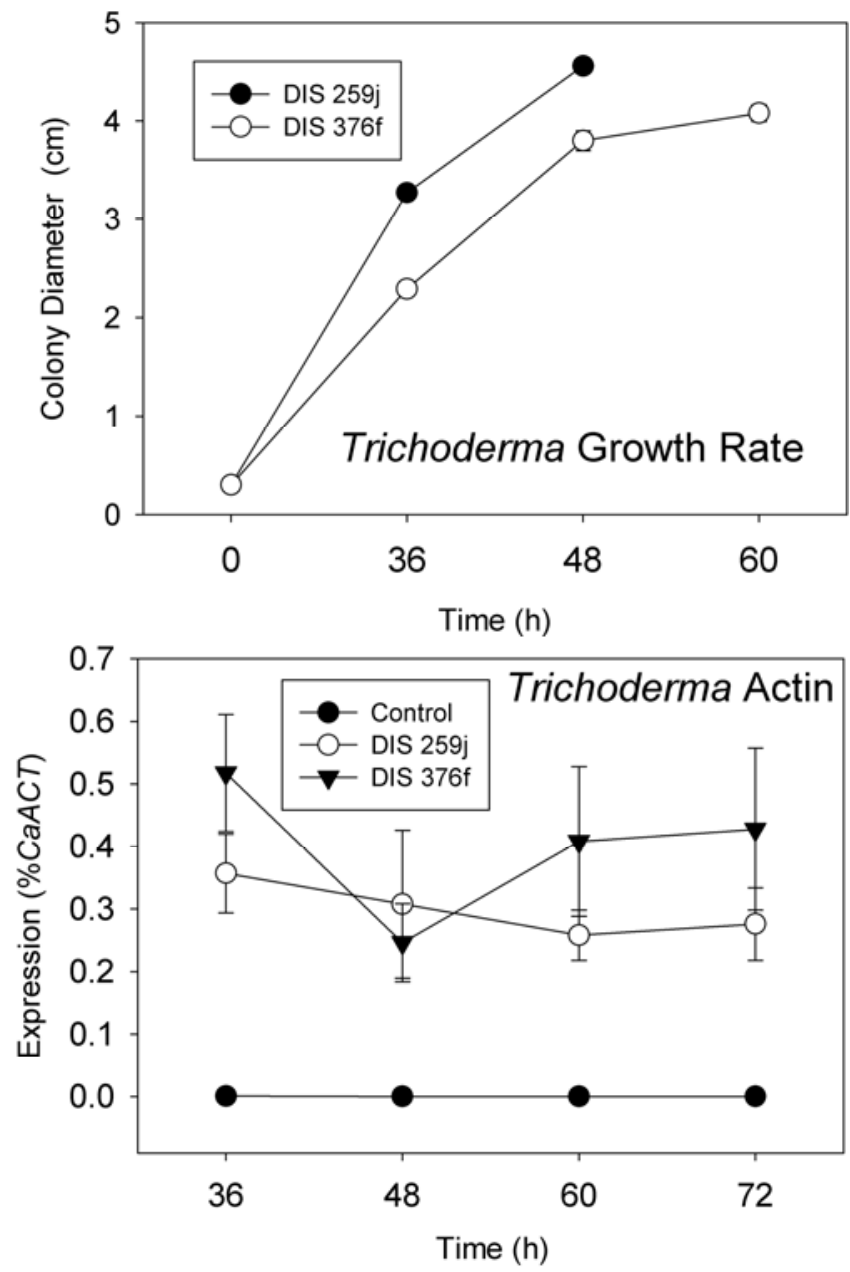

Fig. 6. Initial colonization of pepper roots by Trichoderma isolates DIS $259 \mathrm{j}$ and DIS $376 \mathrm{f}$ as measured by relative amounts of Trichoderma actin (TriACT). Pepper seedlings were grown 14 days and were inoculated with Trichoderma isolates on agar plates. Top, The percentage of the agar plates colonized by Trichoderma isolates was estimated. Bottom, A universal actin primer pair was used to monitor relative Trichoderma activity in the pepper root zone. Pepper roots were harvested 36, 48, 60, and $72 \mathrm{~h}$ after inoculation, and RNA was extracted for quantitative polymerase chain reaction analysis. The data are expressed as TriACT as a percentage of pepper actin $(C a A C T)$. xylem of stems in addition to roots, cotyledons, and plumules (Bailey et al. 2008). Both isolates intensely colonized hot pepper roots but were poor colonizers of pepper stems, when grown under conditions similar to those used in the cacao studies (Bailey et al. 2008). The observations demonstrate that some aspects of specificity in regards to endophytic capability are due to tissue type and general host suitability rather than host identity. Roots are more easily colonized by Trichoderma spp. than stems, seemingly regardless of the plant species (Harman et al. 2004). In terms of host suitability, the developing woody stem of cacao (Bailey et al. 2006, 2008) is a more suitable niche for Trichoderma growth than the stem of pepper. Trichoderma spp. can actively influence their own ability to colonize plant tissues, as demonstrated by the discovery that the $T$. asperellum class 1 hydrophobin TasHydl supports colonization of plant roots, possibly by protecting the hyphal tips from plant defense compounds (Viterbo and Chet 2006).

In 32-day-old seedlings, the Trichoderma isolates altered expression of gene and EST, some with known functions in pepper (Table 3 ) and others with strong sequence similarity to other disease resistance and stress-response genes. This includes genes and EST previously demonstrated to be induced by $P$. capsici (CaLTP1, CaCHI2, CaHMG2, CaPEAS1), viruses (CaPR4, CaPRlO), and bacteria (CaPR1, CaCHI2, CaPO2, CaPO1, CaGA2ox). Genes involved in the hypersensitive response (CaPR4, CaPO2, CaPO1, CaPRl0), responsive to UV exposure $(C a M K 1, C a S C 1)$, and sesquiterpene phytoalexins biosynthesis (CaSC1, CaHMG2, and CaPEAS1) were induced. Genes involved in hormone metabolism and action were also induced, i.e., ethylene (CaPRl, CaCHI2), salicylic acid (CaNPR1), jasmonic acid (CaNPR1, CaJA2), and gibberellic acid $(C a G A 2 o x)$. There is significant overlap in the local (roots) and systemic (leaves) responses to Trichoderma spp. at this late stage of colonization despite the diversity of isolates studied. DIS 259j, DIS 320c, and DIS 376f were the most consistent in altering gene expression (Figs. 2 and 3).

The potential for Trichoderma spp. providing protection against disease caused by Phytophthora spp. has been demonstrated in many cropping systems, although with isolates of relatively few Trichoderma species (Ahmed et al. 2000; Etebarian et al. 2000; Ezziyyani et al. 2005; Hoitink et al. 2006; Khan et al. 2004; Orlikowski 1995; Porras et al. 2007; Smith et al. 1990). Our disease assay included five Trichoderma species (Table 1), four recently identified as new species (Trichoderma caribbaeum var. aequatoriale, T. theobromicola, T. ovalisporum, and T. stilbohypoxyli) from three countries (Cameroon, Ecuador, and Peru), isolated from the canopy of four tropical plant species (Cola praecuta, Theobroma cacao, Theobroma gileri, and Banisteriopsis caapi). T. theobromicola isolate DIS 376f, provided a consistent delay in

Table 5. Expressed sequence tags (EST) used to verify the microarray results and evaluate the early response of pepper seedlings to Trichoderma colonization

\begin{tabular}{|c|c|c|c|c|c|}
\hline EST & Putative function & GenBank ID & tBLASTX & Species & Relatedness $^{\mathrm{y}}$ \\
\hline$C a U N K^{\mathrm{z}}$ & Unknown & NIDB & & & \\
\hline CaMLO & MLO-like protein & BM068042.1 & EU812235 & Vitis vinifera & $4 \mathrm{E}-15 / 71 \%$ \\
\hline$C a G T$ & 1,6-Glucosyl-transferase & GD057261.1 & $\mathrm{AB} 443871$ & Catharanthus roseus & $1 \mathrm{E}-40 / 46 \%$ \\
\hline$C a A C S$ & 1-Aminocyclopropane-1-carboxylate synthase & GD053246.1 & AB434927 & Capsicum chinense & $1 \mathrm{E}-161 / 98 \%$ \\
\hline CaAEC & Auxin efflux carrier component & CA526298.1 & XM_002328968 & Populus trichocarpa & $2 \mathrm{E}-41 / 51 \%$ \\
\hline$C a G A D$ & Glutamate decarboxylase & GD057472.1 & L16977.1 & Petunia hybrida & $1 \mathrm{E}-25 / 87 \%$ \\
\hline $\mathrm{CaCYP}$ & Cytochrome P450 & GD096370 & EU955363 & Zea mays & $6 \mathrm{E}-74 / 63 \%$ \\
\hline CaPER & Anionic peroxidase & BM061283.1 & Y19023 & Lycopersicon esculentum & $8 \mathrm{E}-61 / 89 \%$ \\
\hline CaPOR & Voltage-dependent anion channel & GD111311.1 & AB286178 & Nicotiana tabacum & $2 \mathrm{E}-65 / 68 \%$ \\
\hline CaTR & Tropinone reductase & GD070148.1 & DURTROPR & Datura stramonium & $1 \mathrm{E}-89 / 65 \%$ \\
\hline $\mathrm{CaBKC}$ & Beta-ketoacyl-CoA synthase & GD064384.1 & AJ310739 & Antirrhinum majus & $4 \mathrm{E}-28 / 73 \%$ \\
\hline CaZFP & $\mathrm{C} 3 \mathrm{HC} 4$-type Zinc ring finger & GD124721.1 & NM_123708.2 & Arabidopsis thaliana & $3 e-09 / 82 \%$ \\
\hline
\end{tabular}

${ }^{\mathrm{y}}$ Relatedness values represent expected value to percent identity for each EST.

${ }^{\text {z }}$ CaUNK is an EST included in the microarray (caKS13046E01.ab1_rev) with no equivalent sequence in GenBank. 
disease development (Table 4). T. stilbohypoxyli isolate DIS $259 \mathrm{j}$ and $T$. ovalisporum isolate DIS 70 a also significantly delayed disease development (Table 4). DIS 70a is an endophyte of $T$. cacao and a parasite of $M$. perniciosa and $M$. roreri (Holmes et al. 2004, 2006). Isolates of T. stilbohypoxyli (but not isolate DIS 259j) were shown to be endophytes of cacao and produced metabolites that inhibited $M$. roreri in vitro and on cacao pods but were not parasites of $M$. roreri ( $\mathrm{Lu}$ and Samuels 2003).

Although DIS 259j, DIS 320c, and DIS 376f were the most consistent in altering gene expression, only DIS $259 \mathrm{j}$ and DIS $376 \mathrm{f}$ consistently delayed disease development. DIS 320c failed to protect against $P$. capsici, despite the ability to systemically induce defense responses in pepper. The root damage caused by DIS 320c metabolites may have provided a point of entry for $P$. capsici, negating the benefit of defensegene induction. DIS 70a significantly delayed disease development but induced very few defense-related genes and EST among of the gene repertoire selected here. As DIS 70a and DIS $376 f$ are both parasites of $P$. capsici, it is possible that parasitism contributes to their abilities to delay disease.

In the two volume book series "Trichoderma \& Gliocladium" (Harman and Kubicek 1998), induced resistance by Trichoderma was cited as a needed future work without reference to diseases caused by Phytophthora spp. A review by Harman and associates (2004) discusses Trichoderma-induced resistance to disease in detail but cited only one reference to induced resistance to Phytophthora species (Ahmed et al. 2000). The importance of induced resistance in some Phytophthora-plant pathosystems has been demonstrated (Ahmed et al. 2000; Ezziyyani et al. 2005; Hoitink et al. 2006; Khan et al. 2004) but detailed molecular studies are lacking. The recent detailed molecular studies of resistance induced by Trichoderma species do not address induced resistance in Phytophthora-plant pathosystems (Alfano et al. 2007; Korolev et al. 2007; Segarra et al. 2009; Shoresh and Harman 2008a; Shoresh et al. 2005).
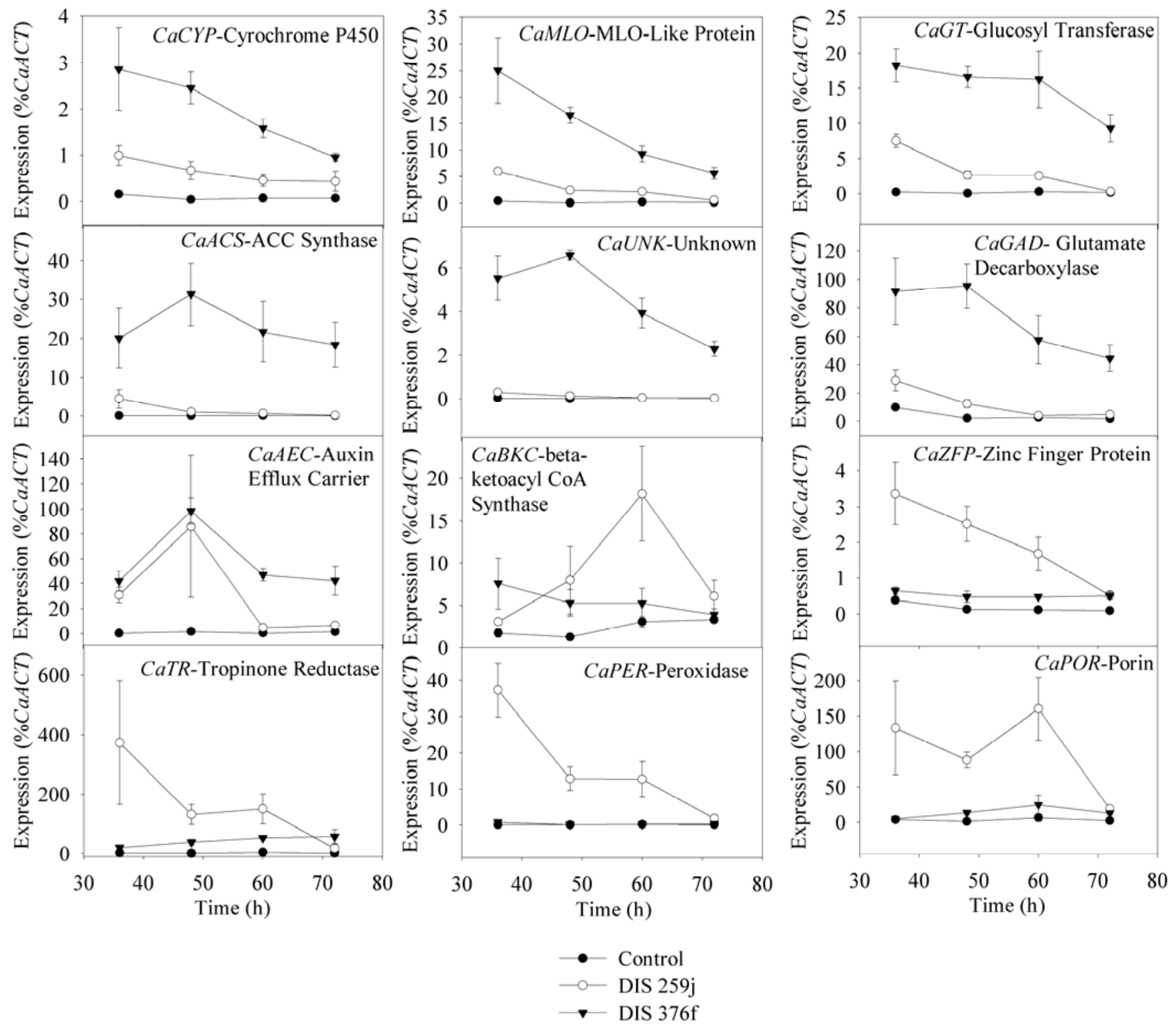

Fig. 7. Expressed sequence tags (EST) encoding stress-related proteins are differentially induced by Trichoderma isolates DIS 259j and DIS 376f. quantitative polymerase chain reaction (qPCR) was carried out, using primers for 12 EST that were indicated to be highly induced, by microarray analysis of RNA samples collected $48 \mathrm{~h}$ after Trichoderma inoculation. Pepper seedlings were grown 14 days and were inoculated with Trichoderma isolates on agar plates. Pepper roots were harvested 36, 48, 60, and 72 hours after inoculation, and RNA was extracted for qPCR analysis. EST include CaCYP, CaMLO, CaGT, CaACS, CaUNK, CaGAD, CaAEC, CaBKC, CaZFP, CaTR, CaPER, and CaPOR. 
In the cases in which detailed molecular analysis of the interaction has taken place, ethylene- and jasmonic acid-dependent induced systemic resistance (ISR) has been implicated (Korolev et al. 2007; Segarra et al. 2009; Shoresh et al. 2005) as opposed to salicylic acid-associated systemic acquired resistance (SAR). It is unclear if this is true in all cases in which Trichoderma spp. induce systemic effects in plants. Alfano and associates (2007) found that, although many aspects of the response of tomato to Trichoderma hamatum isolate 382 were similar to those previously reported in other Trichodermaplant interactions, expression of genes involved in the jasmonate and ethylene signaling pathways of ISR (Loxl, Pall, ETR1, and CTR1) was not altered. Trichoderma spp. also alter expression of genes involved in plant cell metabolism (Alfano et al. 2007), and in the case of T. harzianum isolate T22, proteins involved in carbohydrate metabolism and photosynthesis are up-regulated in association with enhanced plant growth (Shoresh and Harman 2008b).

Depending on the Trichoderma isolate, many different peptides have been identified as elicitors of plant defense. The Trichoderma virens hydrophobin-like (cerato-platanin protein family) elicitor SM1 induces resistance in plants, and its action has been extensively studied in cotton and maize (Djonovic et al. 2006, 2007). SM1-related EST were expressed at high levels by all the Trichoderma isolates studied (data not shown), but when cloned and sequenced, the SM1-related EST lacked the glycosylation site critical to maintaining Trichoderma SM1-related peptides in active form (Vargas et al. 2008). This would suggest that SM1-related peptide elicitors are not involved in the resistance induced by DIS $259 \mathrm{j}$ or DIS $376 \mathrm{f}$. Additional Trichoderma elicitors include the $10-\mathrm{kDa}$ class II hydrophobin Hytra1 (Ruocco et al. 2004, 2007), the 22-kDa xylanase EIX (Bailey et al. 1990; Lotan and Fluhr 1990), the short-chain peptide peptaibols (Viterbo et al. 2007), and the protein Swollenin (Brotman et al. 2008).

DIS 259j and DIS 376f delayed disease development and demonstrated divergent induction patterns for many EST when examined by qPCR analysis (Figs. 7 and 8). Some of these EST have putative functions with potential importance to the P. capsici-pepper pathosystem and Trichoderma-induced plant defense. For example, CaMLO is related to a class of seven transmembrane proteins, the most relevant member of which, in recessive form, confers resistance to powdery mildew (Miklis et al. 2007). The gene product appears to delay cell death in response to powdery mildew, which allows infectionallowing colonization to take place. An obvious question is whether CaMLO impacts the ability of Trichoderma spp. to colonize plant tissues. TcACS putatively encodes an ACC syn- thase. ACC synthase is a primary control point in ethylene biosynthesis (Fluhr and Mattoo 1996), and ethylene induces many plant defense genes, including PR proteins, as has been demonstrated for PRI in pepper (Kim and Hwang 2000). CaPOR encodes a protein related to mitochondrial porin and voltagedependent anion channels (VDAC). In Nicotiana tabacum, VDAC are being studied for their importance in programmed cell death (Tateda et al. 2009). CaGAD putatively encodes a glutamate decarboxylase, a primary enzyme leading to the production of $\gamma$-amino-n-butyric acid (GABA) in plants (Bouché and Fromm 2004). DIS 219b confers drought tolerance in Theobroma cacao through enhanced root growth (Bae et al. 2009). In that study, GABA was shown to accumulate in response to Trichoderma colonization (Bae et al. 2009).

DIS $376 f$ and DIS 259j also differentially induced EST-encoding members of a lipid transfer protein (LTP)-like family of proteins (Fig. 8). LTP play a role in plant responses to biotic and abiotic stress. Plant LTP are a class of small, soluble, and mostly basic proteins found in large gene families in plants (Yeats and Rose 2008). Although the nucleotide and amino-acid sequences diverge, several features are conserved, including eight cysteine residues to form four disulphide bonds, an $\mathrm{N}$-terminus signal peptide that likely directs the proteins to the endoplasmic reticulum, and a retention signal at the C-terminus allowing entry into the secretory pathway. Several functions have been proposed for LTP-like proteins in plants, including facilitating the transfer of lipids between membranes, involvement in cuticle biosynthesis, and fatty acid and acyl coenzyme A carrier proteins. They are generally secreted and associated with the plant cell wall. LTP share a number of structural similarities with oomycetous elicitins. Elicitins are thought to be a class of hydrophobins specific to the oomycetes, including Phytophthora spp. (Yu 1995). The elicitins and tobacco LTP1 compete for the same plasma membrane receptors (Buhot et al. 2004). Additionally, LTP1 binds jasmonic acid and, together, they compete with stronger affinity for the elicitin-binding site and are capable of inducing resistance at a distance from the point of application. The LTP sequences in pepper are diverse, with the most closely related EST to LTP1 in pepper being $C a L T P-M$, which was induced by both isolates. Jung and associates (2003) found LTP1 to be induced in the incompatible interaction between $P$. capsici and pepper but not the compatible interaction. Of the LTP studied, $C a L T P-N$ is most closely related to DIRI (Lascombe et al. 2008; Maldonado et al. 2002). When DIRl is mutated, long-distance induction of SAR-derived resistance is lost. CaLTP- $N$ has a distinct pattern of induction, depending on the isolate being studied. DIS $259 \mathrm{j}$ causes a bimodal induction, with a peak at $48 \mathrm{~h}$ after inoculation and a second rise in expression $72 \mathrm{~h}$ after inoculation. DIS $376 \mathrm{f}$

Table 6. Lipid tranferase protein (LTP)-like related expressed sequence tags (EST) used to verify microarray results and evaluate the early response of pepper seedlings to Trichoderma colonization

\begin{tabular}{|c|c|c|c|c|}
\hline EST & GenBank ID & tBLASTX & Species & Relatedness $^{2}$ \\
\hline CaLTP-A & CA516668.1 & FJ603280 & Tamarix hispida & $6 \mathrm{E}-28 / 59 \%$ \\
\hline CaLTP-B & GD122697 & NM_117322 & Arabidopsis thaliana & $1 \mathrm{E}-37 / 64 \%$ \\
\hline CaLTP-C & CA519148.1 & AF208833 & Capsicum аппиит & $4 \mathrm{E}-32 / 64 \%$ \\
\hline CaLTP-E & $\begin{array}{l}\text { GD092083.1 } \\
\text { GD129887.1 }\end{array}$ & AY554167 & Nicotiana tabacum & $2 \mathrm{E}-44 / 74 \%$ \\
\hline CaLTP-F & BM066625 & Z14088.1 & Solanum lycopersicum & $2 \mathrm{E}-40 / 74 \%$ \\
\hline CaLTP-G & CA523984 & NM 124927 & Arabidopsis thaliana & $0.00002 / 47 \%$ \\
\hline CaLTP-I & GD122016 & AY 496100 & Capsicum аппиит & $4 \mathrm{E}-56 / 68 \%$ \\
\hline CaLTP-J & BM063340.1 & AB041516.1 & Nicotiana tabacum & $4 \mathrm{E}-43 / 83 \%$ \\
\hline CaLTP-K & GD091697 & AB061266 & Solanum tuberosum & $2 \mathrm{E}-32 / 72 \%$ \\
\hline$C a L T P-L$ & GD090271 & NM_112712 & Arabidopsis thaliana & $6 \mathrm{E}-26 / 61 \%$ \\
\hline \multirow[t]{2}{*}{ CaLTP-M } & GD092868.1 & AF118131 & Capsicum аппиит & $1 \mathrm{E}-61 / 84 \%$ \\
\hline & & AF208832 & Capsicum аппиит & $5 \mathrm{E}-52 / 87 \%$ \\
\hline$C a L T P-N$ & GD084957 & NM 124224 & Arabidopsis thaliana & $4 \mathrm{E}-25 / 43 \%$ \\
\hline
\end{tabular}

${ }^{\mathrm{z}}$ Relatedness values represent expected value to percent identity for each EST. 
does not induce $C a L T P-N$ expression until $72 \mathrm{~h}$ after inoculation. When $C a L T P-N$ is expressed in $N$. benthamiana leaves, it provides protection against $P$. nicotianae, reducing AUDPC by $42 \%$ over 5 days (Table 7). The reduction in disease caused by CaLTP-N expression in $N$. benthamiana, taken together with early and systemic induction of CaLTP1/CaLTP-M in pepper seedlings responding to Trichoderma isolates DIS $259 \mathrm{j}$ and DIS 376f, provides evidence for the function of LTP in resistance induced by Trichoderma spp. in pepper.

When isolates DIS 259j and DIS 376f were applied to cacao seedlings using previously published methods (Bailey et al. 2006), the molecular responses observed were similar to those observed with isolate DIS 70a (Bailey et al. 2006) and much less intense than those observed in pepper (unpublished data). Although induced resistance to Phytophthora spp. has been demonstrated in cacao (Arnold et al. 2003; Melnick et al. 2008), only muted molecular responses have been observed. Strong induction of classical plant defense genes, such as genes encoding PR-related proteins, has not yet been observed in cacao. Cacao is heavily colonized by a divergent endophytic fungal community in above- and below-ground tissues (Arnold et al. 2003; Evans et al. 2003; Rubini et al. 2005), and we suggest cacao may promote endophytic colonization by suppressing its induced-resistance responses. On the other hand, annual plant species have been shown to respond to root colonization by specific Trichoderma isolates with a strong defense response (Harman et al. 2004), which limits colonization of plant tissues (Metcalf and Wilson 2001; Yedidia et al. 1999, 2000). The divergent responses of cacao and pepper to colonization by the same endophytic Trichoderma species leads us to suggest the two species may have taken different paths in response to endophytic microbial species.

A complex picture emerges when, under the same conditions, the impact of multiple endophytic Trichoderma isolates on the $P$. capsici-pepper pathosystem are considered. Direct interactions between Trichoderma spp. and pathogens through metabo-
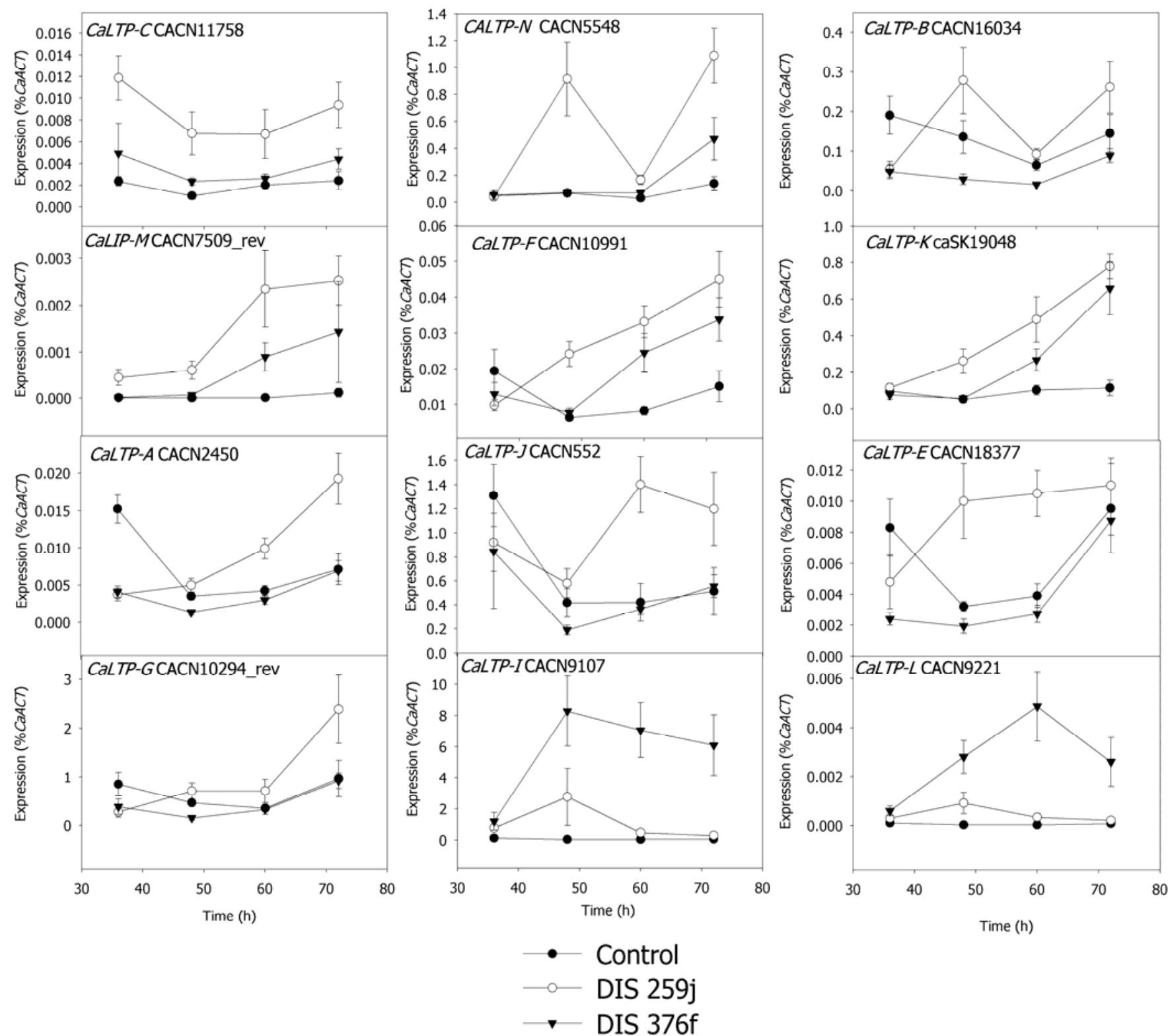

Fig. 8. Expressed sequence tags (EST) encoding members of the lipid tranferase protein (LTP)-like protein family are differentially induced by Trichoderma isolates DIS 259j and DIS 376f. Quantitative polymerase chain reaction (qPCR) was carried out, using primers for LTP-like protein EST that were indicated as being induced, by microarray analysis of RNA samples collected $48 \mathrm{~h}$ after Trichoderma inoculation. Pepper seedlings were grown 14 days and were inoculated with Trichoderma isolates on agar plates. Pepper roots were harvested 36, 48, 60, and $72 \mathrm{~h}$ after inoculation, and RNA was extracted for qPCR analysis. 
lite production and parasitism require the active metabolism of Trichoderma isolates and may benefit from aggressive colonization of plant tissues by endophytic Trichoderma isolates. Endophytic colonization by Trichoderma spp. is dependent on both the tissue and the plant species being colonized.

Of the six Trichoderma isolates studied, DIS 70a, DIS 259j, and DIS $376 \mathrm{f}$ delayed disease development. Isolate 70a, an aggressive root colonizer, was a poor inducer of pepper gene expression both early and late in the Trichoderma-pepper interaction. DIS 259j and DIS 376f were not highly aggressive colonizers of pepper roots, but they strongly induced defenseresponse genes as early as $36 \mathrm{~h}$ after inoculation and as late as 32 days after inoculation. The altered gene expression occurred both in the roots at the site of colonization and systemically in pepper leaves. A unique isolate-dependent pattern of pepper EST induction was observed during initial root colonization, but the systemic pattern of induction tended to converge after 32 days. Transient expression of $C a L T P-N$, a LTP-like protein encoding pepper EST, in $N$. benthamiana leaves reduced disease development in response to $P$. nicotianae inoculation, providing evidence LTP function in Trichoderma-induced resistance to infection by Phytophthora spp.

\section{MATERIALS AND METHODS}

Trichoderma and $P$. capsici isolates and growth.

Six isolates of Trichoderma spp. were used in this study (Table 1). The Trichoderma isolates were maintained on potato dextrose agar (PDA) (Difco, Sparks, MD, U.S.A.) at $25^{\circ} \mathrm{C}$. $P$. capsici isolates R198, RA4, 223, and R8 (Bowers et al. 2007) were maintained in clarified V8 agar $(\mathrm{cV} 8)$ at $25^{\circ} \mathrm{C}$.

\section{P. capsici parasite screening.}

Trichoderma isolates were screened for parasitic ability against $P$. capsici as previously described (Evans et al. 2003; Holmes et al. 2004). P. capsici R198 was inoculated on the edge of 9-cm-diameter plates of $\mathrm{cV} 8$, and the plates were maintained at $25^{\circ} \mathrm{C}$ in the dark for 12 days. A strip of Trichoderma inoculum $(2.5 \times 0.5 \mathrm{~cm})$ was excised from a growing edge of a 5-day-old culture on PDA and was placed at the opposite edge of a 9-cm-diameter $\mathrm{cV} 8$ plate precolonized with $P$. capsici. Three replicate plates were used for each Trichoderma isolate. After 7 days in the dark at $25^{\circ} \mathrm{C}$, samples were removed with a 5-mm-diameter cork borer, starting at the $P$. capsici inoculum side moving to the Trichoderma inoculum side. Each sample was plated on a minimal salts broth agar plate (MIN) (5-cm diameter) (Srinivasan et al. 1992), and the plates were observed over a period of 10 days for growth of the Trichoderma spp., P. capsici, or both.

A water-agar microscope slide assay was also performed to screen the Trichoderma isolates for parasitic ability against $P$. capsici. Glass slides were covered with water agar $(1.5 \%)$. The slides were inoculated $3 \mathrm{~cm}$ apart with 5 -mm-diameter plugs of $P$. capsici R198 and Trichoderma spp. from the growing edge of a 5- to 7-day-old cV8 plate and PDA, respectively. Three replicate slides were used for each Trichoderma isolate. The slides were maintained at room temperature, and the interaction between the two organisms was observed in the area of contact after 5 days. The slides were stained with lacto phenol cotton blue and were photographed with a Nikon Eclipse E600 compound scope (Nikon, Inc., Melville, NY, U.S.A.) equipped with a Nikon digital camera DXM1200 at 600× magnification.

\section{Metabolite production and their impact on $P$. capsici and hot pepper growth.}

The conidia of Trichoderma isolates were harvested from 2week-old cultures grown on PDA at $25^{\circ} \mathrm{C}$, as previously de- scribed (Samuels et al. 2006b). Sterile distilled water (4 ml) was added to the PDA plate, and the plate was scrubbed gently with a bent glass rod. The conidia suspension was filtered through four layers of sterile cheese cloth. Samples of MIN media $(50 \mathrm{ml})$ in $125-\mathrm{ml}$ flasks were inoculated with $1 \mathrm{ml}$ of a $1 \times 10^{6}$ conidia suspension and were incubated in a shaker at $25^{\circ} \mathrm{C}$ and $110 \mathrm{rpm}$ for 7 days. Mycelia were removed using four layers of sterile cheese cloth, and the filtrates were sterilized using a $0.22-\mu \mathrm{m}$ membrane disposable $30-\mathrm{ml}$ syringe filter system (Millipore, Billerica, MA, U.S.A) and were stored at $-20^{\circ} \mathrm{C}$ until used. The filtrates were placed in a $90^{\circ} \mathrm{C}$ water bath for $2 \mathrm{~h}$ to inactivate enzyme activity. An equal volume of the heat-treated filtrate was added to strengthened agar, 3\% MIN. Controls were prepared by replacing the filtrate with the corresponding uninoculated MIN broth. The plates were inoculated centrally with a 5-mm-diameter plug of $P$. capsici $\mathrm{R} 198$ and were incubated at $25^{\circ} \mathrm{C}$. Three replicate plates were used for each isolate. The mean radial growth of $P$. capsici was observed after 5 days.

The effect of Trichoderma metabolites on pepper seedlings was also studied. Metabolites in MIN broth were mixed with an equal volume of $2 \times$ strength Murashige-Skoog (MS) basal salts medium supplemented with $2 \times$ vitamin B5, $0.4 \%$ phytagel, and $0.2 \mathrm{mM}$ morpholineethanesulfonic acid (MES)$\mathrm{KOH}$ ( $\mathrm{pH}$ 5.7). Fourteen-day-old pepper seedlings grown from surface-sterilized seed on $1 \times$ MS basal salts medium supplemented with $1 \times$ vitamin $\mathrm{B} 5,0.2 \%$ phytagel, and $0.1 \mathrm{mM}$ MES-KOH ( $\mathrm{pH}$ 5.7) were transferred to the solidified agar plates containing Trichoderma culture filtrates. The plates were sealed with parafilm, were incubated under fluorescent lights (16-h-light period) at $23^{\circ} \mathrm{C}$ for 4 days, and were observed for root damage. Roots were photographed under a Nikon SMZ1500 dissecting scope (Nikon, Inc.) equipped with a Nikon digital camera (DXM1200) at 50 and 100× magnification. Cross sections of the roots were made and photographed with a Nikon Eclipse E600 compound scope (Nikon) equipped with a Nikon digital camera DXM1200 at 200× magnification.

\section{Endophytic growth-Magenta box study.}

Two agar plugs $(0.5 \mathrm{~cm}$ in diameter $)$ of each Trichoderma isolate were added to a sterilized soil-less mix (Pro-Mix PGX mix; Premier Horticulture Inc., Quakertown, PA, U.S.A.) in double Magenta boxes $(77 \times 77 \times 194 \mathrm{~mm}$; Magenta, Chicago). The Magenta boxes contained $9 \mathrm{~cm}$ of sterile soil-less mix and had four holes $(0.5 \mathrm{~cm}$ diameter $)$ sealed with tape on the bottom. Sterile water $(25 \mathrm{ml})$ was added to the soil-less mix at the time of inoculation. The Magenta boxes were maintained in growth chambers as described below for 14 days before being planted with pepper seed (Capsicum annuum L. cv.

Table 7. Area under the disease progress curve (AUDPC) for Phytophthora nicotiana-challenged Nicotiana benthamiana leaves after infiltration with Agrobacterium tumefaciens EH105 carrying Trichoderma-induced pepper genes $^{\mathrm{y}}$

\begin{tabular}{lcc}
\hline Plasmid construct & AUDPC & Means separation \\
\hline pGD-Empty Vector & 4,102 & $\mathrm{~B}^{\mathrm{z}}$ \\
pGD-CaLTP-N & 2,397 & $\mathrm{~A}$ \\
pGD-CaPOR & 3,252 & $\mathrm{AB}$ \\
pGD-CaMLO & 4,020 & $\mathrm{~B}$ \\
\hline
\end{tabular}

y Three days after infiltration, detached leaves were inoculated with zoospores (approximately $5 \times 10^{4}$ zoospores $/ \mathrm{ml}$ ). Necrosis measurements (\% under droplet) were made for 5 days or until the empty vector control reached a rating of $400 \%$. AUDPC was determined as described by Shanner and Finney (1977), and the data were analyzed by PROC MIXED followed by Tukey's analysis $(P \leq 0.05)$.

${ }^{\mathrm{z}}$ Means not followed by the same letters are significantly different $(P \leq$ $0.05)$. 
Bugang). Seeds were surface-sterilized in 30\% sodium hypochlorite for $5 \mathrm{~min}$, followed by five washes in sterile distilled water. Sterilized seeds were germinated on $1.5 \%$ water-agar plates under fluorescent lights for 4 days at $25^{\circ} \mathrm{C}$. Three germinated seeds were planted in each Magenta box $3 \mathrm{~cm}$ deep into the sterile soil-less mix with or without Trichoderma spp. Seedlings were grown with a 12-h-light and 12-h-dark cycle at $25^{\circ} \mathrm{C}$. The irradiance was $50 \mu \mathrm{mol} \mathrm{m} \mathrm{m}^{-2} \mathrm{~s}^{-1}$ photosynthetically active radiation. After 35 days, the pepper seedlings (two per Magenta box) were dissected, and approximately 1-cm tissue sections of roots and stems were plated on $1 \times$ corn meal dextrose agar (Becton Dickinson and Company, Sparks, MD, U.S.A.). For each seedling the lower stem was cut into four sections and one root section was plated for each seedling. Treatments consisted of six replications. The plated plant sections were incubated on the lab bench for 5 to 7 days, until the Trichoderma isolates grew out of the pepper-tissue sections and were assessed as positive or negative for colonization.

\section{Induced resistance and disease suppression assay.}

Preparation of Trichoderma inoculum. Hot pepper (Capsicum annuum L. cv. Bugang) seeds were sown into Trichodermaamended Pro-Mix PGX mix. The Trichoderma inocula were prepared using Biodac granular carrier (20/50; Kadant Gran Tek, Inc., Green Bay, WI, U.S.A.). Biodac (50 g) was aliquoted into mycobags (Unicorm Imp. \& Mfg. Corp., Commerce, TX, U.S.A.) with $50 \mathrm{ml}$ of diluted V8 juice (10\%). The bags were sealed and were autoclaved for $60 \mathrm{~min}$ twice over 2 days. Four plugs (0.5-cm diameter) of each Trichoderma isolate, grown on PDA agar plates for 3 to 5 days, were added to the bags. The bags were resealed and were incubated at room temperature for 3 weeks.

Preparation of $\mathrm{P}$. capsici inoculum. Petri dishes containing cV8 juice agar (Bowers and Mitchell 1990) were inoculated with $P$. capsici isolates R1198, RA4, 223, and R899 (Bowers et al. 2007). The plates were incubated at room temperature for 2 days in the dark and an additional 3 days under light. Biodac (100 g) was mixed with $100 \mathrm{ml}$ of cV8 and added to a mycobag, and the mycobag was autoclaved for $60 \mathrm{~min}$ on two consecutive days. For each $P$. capsici isolate, four $1-\mathrm{cm}^{2}$ agar plugs were added to the mycobag and the mycobag was incubated at room temperature for 2 to 4 weeks.

Inoculation of hot pepper with Trichoderma spp. Trichoderma-inoculated Biodac was added into Pro-Mix PGX mix $(0.1 \%, \mathrm{vol} / \mathrm{vol})$, and seeds were sown in square pots $(5 \times 5 \times 6$ $\mathrm{cm})$. Tap water was applied until the seeds germinated, after which the seedlings were watered with Miracle-Gro (Scotts Miracle-Gro Co., Marysville, OH, U.S.A.) twice a week. Seedlings were grown in a controlled environment chamber (model M-2; EGC Corp., Chagrin Falls, OH, U.S.A.) with a 12 -h-light and 12 -h-dark photoperiod at $25^{\circ} \mathrm{C}$. The irradiance was $100 \mu \mathrm{mol} \mathrm{m} \mathrm{m}^{-2} \mathrm{~s}^{-1}$ photosynthetically active radiation. Relative humidity was not controlled in this experiment, but relative humidity was always above 50\%. After 32 days of growth, leaves above the fifth node and roots were harvested for qPCR.

Real-time reverse transcriptase $q P C R$. Induced resistance was also observed by real-time reverse transcriptase qPCR. Total RNA and cDNA synthesis, qPCR conditions, and data analysis were performed as described by Bailey and associates (2006). Relative transcript levels of each gene were normalized with respect to pepper actin transcript levels (\%CaACT). Mean values were obtained from six biological replications.

Transplanting Trichoderma-colonized hot pepper into $\mathrm{P}$. capsici-inoculated soils. P. capsici in Biodac was added to moistened soil at a rate of $0.15 \mathrm{~g}$ per liter of soil 2 days prior to transplanting pepper. Individual pepper plants (42-day-old Trichoderma-inoculated or uninoculated controls) were trans- planted into empty $7.62-\mathrm{cm}$ pots and the remaining volume of the pot was filled with soil infested with $P$. capsici. Three experiments were carried out consisting of 10, 20, and 20 replicate pots per treatment, with one plant per pot, arranged in a completely randomized design. Days to symptom expression was determined for each plant for the 14 days after transplanting. The number of days without symptoms was calculated for each seedling as the number of days until symptoms appeared minus one, with the minimum being zero and the maximum being 13. The data for days without symptoms was combined over the three experiments for analysis. The data were analyzed as a two-way factorial with treatment (control plus six Trichoderma isolates) and experiment (experiments one, two and three) as factors, using the PROC MIXED procedure of SAS 9.1 (SAS Institute Inc., Raleigh, NC, U.S.A.), and means were separated using Tukey's studentized range test.

\section{The early responses}

\section{in the hot pepper-Trichoderma interaction.}

Seedling growth and inoculation on artificial media. Pepper seedlings were grown and inoculated with Trichoderma spp. on agar plates to determine the early responses in the pepperTrichoderma interaction. Pepper seeds were surface-sterilized in $30 \%$ sodium hypochlorite for $10 \mathrm{~min}$, followed by three washes in sterile distilled water. Sterile seeds were placed on plates containing $1 \times$ strength MS basal salts medium supplemented with $1 \times$ vitamin $\mathrm{B} 5,0.2 \%$ phytagel, and $0.1 \mathrm{mM}$ MES-KOH ( $\mathrm{pH}$ 5.7), and the plates were sealed with parafilm. The plates were incubated under fluorescent lights (16-h light period) at $23^{\circ} \mathrm{C}$ for 14 or 24 days, depending on the study. The plates were inoculated with PDA plugs $(0.5-\mathrm{cm}$ diameter $)$ of the Trichoderma isolates, and the Trichoderma isolates were allowed to colonize the pepper seedlings. Four PDA plugs were applied per plate. PDA plugs without Trichoderma were used on control plates. Pepper roots were harvested 36, 48, 60, or $72 \mathrm{~h}$ after inoculation, depending on the study. Total RNA was extracted as described above.

Pepper gene expression in response to initial Trichoderma colonization. Eight EST listed in Table 3 were studied by qPCR analysis of pepper root RNA harvested from plategrown seedlings $72 \mathrm{~h}$ after inoculation with all six Trichoderma isolates. Each treatment combination included six independent replications. Expression of TriACT was also determined using consensus primers generated from sequences available in GenBank. The data are presented in two ways: i) for fungal actin (TriACT) and hot pepper genes and EST, EST expression as a percentage of hot pepper actin expression and ii) for hot pepper genes and EST, the fold increase in EST expression relative to TriACT expression $\left(\mathrm{FI}_{/ \% \text { Tact }}\right)$. This was accomplished by subtracting the mean expression level relative to plant actin for each EST in the controls $\left(\operatorname{Exp}_{\mathrm{ct}}\right)$ from each EST expression level relative to plant actin in individual treated samples $\left(\operatorname{Exp}_{\mathrm{trt}}\right)$ and then dividing the increase in expression level in individual Trichoderma treated samples $\left(\operatorname{Exp}_{\mathrm{trt}}-\operatorname{Exp}_{\mathrm{ct}}\right)$ by the mean expression level relative to plant actin in the control samples $\left(\operatorname{Exp}_{\mathrm{ct}}\right)$, yielding the fold induction for each sample relative to plant actin. The fold induction for each sample relative to plant actin was divided by the percentage of TriACT relative to plant actin $\left(\% \mathrm{Exp}_{\text {Tact }}\right)$ in each sample, yielding the fold increase relative to the percent $\operatorname{TriACT}\left(\mathrm{FI}_{/ \% \text { Tact }}\right)$ :

$$
\left(\mathrm{FI}_{/ \% \text { Tact }}\right)=\left[\left(\operatorname{Exp}_{\text {trt }}-\operatorname{Exp}_{\mathrm{ct}}\right) /\left(\operatorname{Exp}_{\mathrm{ct}}\right)\right] /\left(\% \operatorname{Exp}_{\text {Tact }}\right) \text {. }
$$

In order to identify new candidate EST for study of early gene expression in the pepper-Trichoderma interaction, experiments were performed with a single replication pepper microarray. EST identified in the microarray results were studied by qPCR analysis of pepper root RNA harvested from plate- 
grown seedlings $36,48,60$, and $72 \mathrm{~h}$ after inoculation with Trichoderma isolates DIS259j and DIS376f. Each treatment combination included six independent replications. A total of 24 EST (Tables 5 and 6) were evaluated over the full timecourse, including 12 members of the pepper LTP-like gene family. Expression of TriACT was determined by qPCR analysis, as described above. Analysis of variance was conducted on the data for TriACT, and each pepper EST was expressed as percent plant actin, using PROC GLM followed by a Tukey test using SAS 9.2 (SAS Institute Inc.).

\section{Cloning of CaLTP-N, CaPOR, and CaMLO and the impact of their Agrobacterium tumefaciens-mediated protein expression on the $N$. benthamiana-P. nicotianae interaction.}

The full-length mRNAs for $C a L T P-N$ and $C a P O R$ were available in GenBank. In order to clone the full-length of $\mathrm{CaMLO}, 5^{\prime}$ rapid amplification of cDNA ends (RACE) was performed, using the RACE system according to manufacturer's recommendation (Invitrogen, Carlsbad, CA, U.S.A.). The RACE products were cloned into pCR2.1-TOPO vector (Invitrogen) for sequencing. DNA sequences were determined by COSMO Genetech (Seoul, Korea). A full length of CaMLO (1,745 bp), consisting of a 1,236-bp open reading frame encoding 411 amino acids, was obtained. The sequence of $C A M L O$ was deposited in GenBank (HQ324112). The deduced amino-acid sequences of $C a M L O$ showed highest identity $(67 \%)$ with the MLO-like protein 6 of Vitis vinifera $(\mathrm{E}$-value $=2 \mathrm{e}-140)$.

The pGD binary vector system was used for expressing CaLTP-N, CaPOR, and CaMLO in N. benthamiana leaves as described by Goodin and associates (2002). CaLTP-N, $C a P O R$, and $C a M L O$ were amplified from pepper cDNA and were cloned into TOPO vector (Invitrogen). After sequence confirmation, the correct size fragments from XhoI/BamHI (CaLTP-N, CaPOR) and XhoI/HindIII (CaMLO) digests were inserted into the XhoI/BamHI and XhoI/HindIII sites of pGD vector, respectively. pGD-CaLTP-N, pGD-CaPOR, and pGDCaMLO were transformed into Agrobacterium tumefaciens EH105 and were infiltrated into the abaxial side of $N$. benthamiana leaves, as described by Lim and associates (2009). A final EH105 concentration of 0.4 optical density at $600 \mathrm{~nm}$ was applied in this experiment. Three to four leaves were infiltrated on each plant, and two plants were infiltrated with each of two independent isolates of each construct.

After 3 days, zoospores were liberated from 7- to 10-dayold cultures of $P$. nicotianae, following modification from Lawrence (1978) and two to four 20- $\mu$ l drops (approximately 5 $\times 10^{4}$ zoospores $/ \mathrm{ml}$ ) were applied to the abaxial side of freshly detached previously infiltrated leaves maintained on wetted Whatman paper in petri dishes. Percent necrosis measurements were made for each drop on each leaf over the next 5 days or until the empty vector control reached a necrosis rating of $400 \%$ of the original drop area. AUDPC was determined as described by Shanner and Finney (1977). The experiment was repeated four times, and the combined data were analyzed by PROC MIXED followed by Tukey analysis using SAS 9.2 and a significance level of $P \leq 0.05$. The expression of the pepper genes in $N$. benthamiana leaves was monitored by qPCR, using the methods described above. Total RNA was isolated from $N$. benthamiana leaves 3 days after agroinfiltration, using the Qiagen RNeasy plant mini kit with the optional on-column DNase step (Qiagen Inc., Valencia, CA, U.S.A.).

\section{ACKNOWLEDGMENTS}

This work was partially supported by the grant from the BioGreen 21 program of Rural Development and Administration, Republic of Korea.
The United States Department of Agriculture is an equal opportunity provider and employer.

\section{LITERATURE CITED}

Ahmed, A. S., Sanchez, C. P., and Candela, M. E.2000. Evaluation of induction of systemic resistance in pepper plants (Capsicum annuum) to Phytophthora capsici using Trichoderma harzianum and its relation with capsidiol accumulation. Eur. J. Plant Pathol. 106:817-824.

Alfano, G., Lewis Ivey, M. L., Cakir, C., Bos, J. I. B., Miller, S. A., Madden, L. V., Kamoun, S., and Hoitink, H. A. J. 2007. Systemic modulation of gene expression in tomato by Trichoderma hamatum 382. Phytopathology 97:429-437.

Arnold, A. E., Mejía, L. C., Kyllo, D., Rojas, E. I., Maynard, Z., Robbins, N., and Herre, E. A. 2003. Fungal endophytes limit pathogen damage in a tropical tree. Proc. Nat. Acad. Sci. U.S.A. 100:15649-15654.

Back, K., He, S., Kim, K. U., and Shin, D. H. 1998. Cloning and bacterial expression of sesquiterpene cyclase, a key branch point enzyme for the synthesis of sesquiterpenoid phytoalexin capsidiol in UV-challenged leaves of Capsicum annuum. Plant Cell Physiol. 39:899-904.

Bae, H., Sicher, R. C., Kim, M. S., Kim, S-H., Strem, M. D., Melnick, R. L., and Bailey, B. A. 2009. The beneficial endophyte Trichoderma hamatum isolate DIS $219 \mathrm{~b}$ promotes growth and delays the onset of the drought response in Theobroma cacao. J. Exp. Bot.60:3279-3295.

Bailey, B. A., and Lumsden, R. D. 1998. Direct effects of Trichoderma and Gliocladium on plant growth and resistance to pathogens. Pages 185204 in: Trichoderma and Gliocladium, Vol. 2, Kubicek, C. P., and Harman, G. E., Eds., Taylor and Francis, Ltd, Bristol, PA.

Bailey, B. A., Dean, J. F. D., and Anderson, J. D. 1990. An ethylene biosynthesis-inducing endoxylanase elicits electrolyte leakage and necrosis in Nicotiana tabacum cv. Xanthi leaves. Plant Physiol. 94:1849-1854.

Bailey, B. A., Bae, H., Strem, M. D., Roberts, D. P., Thomas, S. E., Samuels, G. J., Choi, I-Y., and Holmes, K. A. 2006. Fungal and plant gene expression during the colonization of cacao seedlings by endophytic isolates of four Trichoderma species. Planta 224:1449-1464.

Bailey, B. A., Bae, H., Strem, M. D., Crozier, J., Thomas, S. E., Samuels, G. J., Vinyard, B. T., and Holmes, K. A. 2008. Antibiosis, mycoparasitism, and colonization success for endophytic Trichoderma isolates with biological control potential in Theobroma cacao. Biol. Control 46:24-35.

Birch, P. R. J., Rehmany, A. P., Pritchard, L., Kamoun, S., and Beynon, J.L. 2006. Trafficking arms: Oomycete effectors enter host plant cells. Trends Microbiol.14:8-11.

Bouché, N., and Fromm, H. 2004. GABA in plants: Just a metabolite? Trends Plant Sci. 9:110-115.

Bowers, J. H., and Mitchell, D. J. 1990. Effect of soil-water matric potential and periodic flooding on mortality of pepper caused by Phytophthora capsici. Phytopathology 80:1447-1450.

Bowers, J. H., Bailey, B. A., Hebbar, P. K., Sanogo, S., and Lumsden, R.D. 2001. The impact of plant diseases on world chocolate production. Plant Health Prog. DOI:10.1094/PHP-2001-0709-01-RV. Published online.

Bowers, J. H., Martin, F. N., Tooley, P. W., and Luz, E. D. M. N. 2007. Genetic and morphological diversity of temperate and tropical isolates of Phytophthora capsici. Phytopathology 97:492-503.

Brotman, Y., Briff, E., Viterbo, A., and Chet, I. 2008. Role of swollenin, an expansin-like protein from Trichoderma, in plant root colonization. Plant Physiol. 147:779-789.

Buhot, N., Gomès, E., Milat, M. L., Ponchet, M., Marion, D., Lequeu, J., Delrot, S., Coutos-Thévenot, P., and Blein, J. P. 2004. Modulation of the biological activity of a tobacco LTP1 by lipid complexation. Mol. Biol. Cell 15:5047-5052.

Burdon, J. J., and Thrall, P. H. 2009. Coevolution of plants and their pathogens in natural habitats. Science 324:755-756.

Chet, I., Benhamou, N., and Haran, S. 1998. Mycoparasitism and lytic enzymes. Pages 153-171 in: Trichoderma and Gliocladium, Vol. 2. G. E. Harman and C.P. Kubicek, eds. Taylor and Francis, London.

Choi, H. W., Kim, Y. J., Lee, S. C., Hong, J. K., and Hwang, B. K. 2007. Hydrogen peroxide generation by the pepper extracellular peroxidase $\mathrm{CaPO} 2$ activates local and systemic cell death and defense response to bacterial pathogens. Plant Physiol. 145:890-904.

Djonovic, S., Pozo, M. J., Dangott, L. J., Howell, C. R., and Kenerley, C. M. 2006. Sm1, a Proteinaceous elicitor secreted by the biocontrol fungus Trichoderma virens induces plant defense responses and systemic resistance. Mol. Plant-Microbe Interact. 19:838-853.

Djonovic, S., Vargas, W. A., Kolomiets, M. V., Horndeski, M., Wiest, A., and Kenerley, C. M. 2007. A proteinaceous elicitor Sm1 from the beneficial fungus Trichoderma virens is required for induced systemic resistance in maize. Plant Physiol. 145:875-889.

Do, H. M., Hong, J. K., Jung, H. W., Kim, S. H., Ham, J. H., and Hwang, B. K. 2003. Expression of peroxidase-like genes, $\mathrm{H}_{2} \mathrm{O}_{2}$ production, and 
peroxidase activity during the hypersensitive response to Xanthomonas campestris pv. vesicatoria in Capsicum annuum. Mol. Plant-Microbe Interact. 16:196-205.

Etebarian, H. R., Scott, E. S., and Wicks, T. J. 2000. Trichoderma harzianum T39 and T. virens DAR 74290 as potential biological control agents for Phytophthora erythroseptica. Eur. J. Plant Pathol. 106:329337

Evans, H. C., Holmes, K. A., and Thomas, S. E. 2003. Endophytes and mycoparasites associated with an indigenous forest tree, Theobroma gileri, in Ecuador and a preliminary assessment of their potential as biocontrol agents of cocoa diseases. Mycol. Prog. 2:149-160.

Ezziyyani, M., Requena, M. E., and Candela, M. E. 2005. Production of PR proteins during the induction of resistance to Phytophthora capsici in pepper (Capsicum annuum L.) plants treated with Trichoderma harzianum. An. Biol. 27:143-153.

Fluhr, R., and Mattoo, A. K. 1996. Ethylene-biosynthesis and perception. CRC Crit. Rev. Plant Sci. 15:479-523.

Goodin, M. M., Dietzgen, R. G., Schichnes, D., Ruzin, S., and Jackson, A O. 2002. pGD vectors: Versatile tools for the expression of green and red fluorescent protein fusions in agroinfiltrated plant leaves. Plant J. 3:375-383.

Guest, D. 2007. Black pod: Diverse pathogens with a global impact on cocoa yield. Phytopathology 97:1650-1653

Ha, S. H., Kim, J. B., Hwang, Y. S., and Lee, S. W. 2003. Molecular characterization of three 3-hydroxy-3-methylglutaryl-CoA reductase genes including pathogen-induced Hmg2 from pepper (Capsicum annuиm). Biochim Biophys. Acta 1625:253-260.

Hanada, R. E., de Jorge Souza, T., Pomella, A. W. V., Hebbar, K. P., Pereira, J. O., Ismaiel, A., and Samuels, G. J. 2008. Trichoderma martiale sp. nov., a new endophyte from sapwood of Theobroma cacao with a potential for biological control. Mycol. Res. 112:1335-1343.

Harman, G. E., and Kubicek, C. P. 1998. Pages 153-171 in: Trichoderma and Gliocladium, Vol. 1 and 2. Taylor and Francis, London.

Harman, G. E., Howell, C. R., Viterbo, A., and Chet, I. 2004. Trichoderma spp.-Opportunistic avirulent plant symbionts. Nat. Rev. Microbiol. 2:43-56

Hoitink, H. A., Madden, L. V., Dorrance, A. E. 2006. Systemic resistance induced by Trichoderma spp.: Interactions between the host, the pathogen, the biocontrol agent, and soil organic matter quality. Phytopathology 96:186-189.

Holmes, K. A., Schroers, H., Thomas, S. E., Evans, H. C., and Samuels, G J. 2004. Taxonomy and biocontrol potential of a new species of Trichoderma from the Amazon basin of South America. Mycol. Prog. 3:199210

Holmes, K. A., Krauss, U., and Samuels, G. J. 2006. Trichoderma ovalisporum, a novel biocontrol agent of frosty pod rot (Moniliophthora roreri) of cocoa (Theobroma cacao): From discovery to field. Pages 5465 in: Proceedings of the First International Conference on Plant Microbe Interactions: Endophytes and Biocontrol Agents. April 18-22, 2005. S. Sorvari, and O. Toldi, eds., Saariselka, Lapland, Finland.

Hong, J. K., Jung, H. W., Kim, Y. J., and Hwang, B. K. 2000. Pepper gene encoding a basic class II chitinase is inducible by pathogen and ethephon. Plant Sci. 159:39-49.

Howell, C. R. 1998. The role of antibiosis in biocontrol. Pages 173-184 in: Trichoderma and Gliocladium, Vol. 2. G.E. Harman, C.P. Kubicek, eds. Taylor and Francis, London.

Howell, C. R. 2003. Mechanisms employed by Trichoderma species in the biological control of plant diseases: The history and evolution of current concepts. Plant Dis. 87:4-10.

Jung, H. W., Kim, W., and Hwang, B. K. 2003. Three pathogen-inducible genes encoding lipid transfer protein from pepper are differentially activated by pathogens, abiotic, and environmental stresses. Plant Cell Environ. 26:915-928.

Khan, J., Ooka, J. J., Miller, S. A., Madden, L. V., and Hoitink, H. A. J. 2004. Systemic resistance induced by Trichoderma hamatum 382 in cucumber against Phytophthora crown rot and leaf blight. Plant Dis. $88: 280-286$

Kim, E., and Hwang, B. K. 1992. Virulence to Korean pepper cultivars of isolates of Phytophthora capsici from different geographic areas. Plant Dis. 76:486-489.

Kim, Y. J., anad Hwang, B. K. 2000. Pepper gene encoding a basic pathogenesis-related 1 protein is pathogen and ethylene inducible. Physiol. Plant. 108:51-60.

Korolev, N., David, R., and Elad, Y. 2007. The role of phytohormones in basal resistance and Trichoderma-induced systemic resistance to Botrytis cinerea in Arabidopsis thaliana. Biocontrol 53:667-668.

Lascombe, M. B., Bakan, B., Buhot, N., Marion, D., Blein, J. P., Larue, V., Lamb, C., and Prangé, T. 2008. The structure of "defective in induced resistance" protein of Arabidopsis thaliana, DIR1, reveals a new type of lipid transfer protein. Protein Sci. 17:1522-1530.
Lawrence, J. S. 1978. Evaluation of methods for assessing resistance of cocoa (Theobroma cacao L.) cultivars and hybrids to Phytophthora palmivora (Butler) Butler. Bol. Tec. 62:47.

Lim, H. S., Bragg, J. N., Ganesan, U., Ruzin, S., Schichnes, D., Lee, M. Y., Vaira, A. M., Ryu, K. H., Hammond, J., and Jackson, A. O. 2009. Subcellular localization of the barley stripe mosaic virus triple gene block proteins. J. Virol. 83:9432-48.

Lotan, T., and Fluhr, R. 1990. Xylanase, a novel elicitor of pathogenesisrelated proteins in tobacco, uses a non-ethylene pathway for induction. Plant Physiol. 93:811-817.

Lu, B., and Samuels, G. J. 2003. Hypocrea stilbohypoxyli and its Trichoderma koningii-like anamorph: A new species from Puerto Rico on Stilbohypoxylon muelleri. Sydowia 55:255-266.

Maldonado, A. M., Doerner, P., Dixon, R. A., Lamb, C. J., and Cameron, R. K.. 2002. A putative lipid transfer protein involved in systemic resistance signalling in Arabidopsis. Nature 419:399-403.

Melnick, R. L., Zidack, N. K., Bailey, B. A., Maximova, S. N., Guiltinan, M., and Backman, P. A. 2008. Bacterial endophytes: Bacillus spp. from vegetable crops as potential Biol. Control agents of black pod rot of cacao. Biol. Control 46:46-56.

Metcalf, D. A., and Wilson, C. R. 2001. The process of antagonism of Sclerotium cepivorum in white rot affected onion roots by Trichoderma koningii. Plant Pathol. 50:249-257.

Meyer, G. D., Bigirimana, J., Elad, Y., and Hofte, M. 1998. Induced systemic resistance in Trichoderma harzianum T39 biocontrol of Botrytis cinerea. Eur. J. Plant Pathol. 104:279-286.

Miklis, M., Consonni, C., Bhat, R. A., Lipka, V., Schulze-Lefert, P., and Panstruga, R. 2007. Barley MLO modulates actin-dependent and actinindependent antifungal defense pathways at the cell periphery. Plant Physiol. 144:1132-1143.

Orlikowski, L. B. 1995. Studies of biological control of Phytophthora cryptogea Pethybr. et Laff. II. Effectiveness of Trichoderma and Gliocladium spp. in the control of Phytophthora foot rot of gerbera. J. Phytopathol. 143:341-343.

Porras, M., Barrau, C., Arroy, F. T., Santos, B., Blanco, C., and Romero, F 2007. Reduction of Phytophthora cactorum in strawberry fields by Trichoderma spp. and soil solarization. Plant Dis. 91:142-146.

Rubini, M. R., Silva-Ribeiro, R. T., Pomella, A. W. V., Maki, C. S., Araújo, W. L., dos Santos, D. R., and Azevedo, J. L. 2005. Diversity of endophytic fungal community of cacao (Theobroma cacao L.) and Biol. Control of Crinipellis perniciosa, causal agent of witches' broom disease. Int. J. Biol. Sci. 1:24-33

Ruocco, M., Lanzuise, S., Woo, S., Ambrosino, P., Marra, D., Turrà, D. Gigante, S., Formisano, E., Scala, F., Kip, D. J., de Wit, P. J. G. M., and Lorito, M. 2004. The Trichoderma-plant interaction is mediated by avirulence proteins produced by the fungus. J. Plant Pathol. 86:297.

Ruocco, M., Lanzuise, S., Turrà, D., Vinale, F., Marra, R., Woo, S. L., and Lorito, M. 2007. Hytra1 from the beneficial fungus Trichoderma harzianum T22 is an elicitor of defense responses in plants. J. Plant Pathol. 89:S21.

Samuels, G. J., and Ismaiel, A. 2009. Trichoderma evansii and T. lieckfeldtiae two new T. hamatum-like species. Mycologia 101:142-156.

Samuels, G. J., Pardo-Schultheiss, R. A., Hebbar, K. P., Lumsden, R. D. Bastos, C. N., Costa, J. C., and Bezerra, J. L. 2000. Trichoderma stromaticum sp. nov., a parasite of the cacao witches broom pathogen. Mycol Res. 104:760-764.

Samuels, G. J., Dodd, S. L., Lu, B-S., Petrini, O., Schroers, H-J., and Druzhinina, I. S. 2006a. The Trichoderma koningii aggregate species. Stud. Mycol 56:67-133.

Samuels, G. J., Suarez, C., Solis, K., Holmes, K. A., Thomas, S. E., Ismaiel, A. A., and Evans, H. C. 2006b. Trichoderma theobromicola and T. paucisporum: two new species from South America. Mycol. Res. 110:381-392.

Segarra, G., Van der Ent, S., Trillas, I., and Pieterse, C. M. J. 2009. MYB72, a node of convergence in induced systemic resistance triggered by a fungal and a bacterial beneficial microbe. Plant Biol. 11:90-96.

Shanner, G., and Finney, R. E. 1977. The effect of nitrogen fertilization on the expression of slow-mildewing resistance in Knox wheat. Phytopathology 67:1051-1056.

Shin, R., Lee, G. J., Park, C. J., Kim, T. Y., You, J. S., Nam, Y. W., and Paek, K. H. 2001. Isolation of pepper mRNAs differentially expressed during the hypersensitive response to tobacco mosaic virus and characterization of a proteinase inhibitor gene. Plant Sci. 161:727-737.

Shoresh, M., and Harman, G. E. 2008a. The molecular basis of shoot responses of maize seedlings to Trichoderma harzianum T22 inoculation of the root: A proteomic approach. Plant Physiol. 147:2147-2163.

Shoresh, M., and Harman, G. E. 2008b. The relationship between increased growth and resistance induced in plants by root colonizing microbes. Plant Signal. Behav. 3:737-739.

Shoresh, M., Yedidia, I., and Chet, I. 2005. Involvement of jasmonic 
acid/ethylene signaling pathway in the systemic resistance induced in cucumber by Trichoderma asperellum T203. Phytopathology 95:76-84.

Smith, V. L., Wilcox, W. F., and Harman, G. E. 1990. Potential for biological control of Phytophthora root and crown rots of apple by Trichoderma and Gliocladium spp. Phytopathology 80:880-885.

Srinivasan, U., Staines, H. J., and Bruce, A. 1992. Influence of media type on an antagonistic modes of Trichoderma spp. against wood decay basidiomycetes. Mater. Organismen 27:301-321.

Stone, J. K., Bacon, C. W., and White Jr., J. F. 2000. An overview of endophytic microbes: Endophytism defined. Pages 3-29 in: Microbial Endophytes. C. W. Bacon and J. F. White, eds. Marcel Dekker, New York.

Tateda, C., Yamashita, K., Takahashi, F., Kusano, T., and Takahashi, Y. 2009. Plant voltage-dependent anion channels are involved in host defense against Pseudomonas cichorii and in Bax-induced cell death. Plant Cell Rep. 28:41-51.

Tian, D., and Babadoost, M. 2004. Host range of Phytophthora capsici from pumpkin and pathogenicity of isolates. Plant Dis. 88:485-489.

Viterbo, A., and Chet, I. 2006. TasHyd1, a new hydrophobin gene from the biocontrol agent Trichoderma asperellum, is involved in plant root colonization. Mol. Plant Pathol. 7:249-258.

Viterbo, A., Wiest, A., Brotman, Y., Chet, I., and Kenerley, C. 2007. The 18 mer peptaibols from Trichoderma virens elicit plant defence responses. Mol. Plant Path. 8:737-746.
Vargas, W. A., Djonovic, S., Sukno, S. A., and Kenerley, C. M. 2008. Dimerization controls the activity of fungal elicitors that trigger systemic resistance in plants. J. Biol. Chem. 283:19804-19815.

Yeats, T. H., and Rose, J. K. 2008. The biochemistry and biology of extracellular plant lipid-transfer proteins (LTPs). Protein Sci. 17:191-198.

Yedidia, I., Benhamou, N., and Chet, I. 1999. Induction of defense responses in cucumber plants (Cucumis sativus L.) by the biocontrol agent Trichoderma harzianum. Appl. Environ. Microbiol. 65:1061-1070.

Yedidia, I., Benhamou, N., Kapulnik, Y., and Chet, I. 2000 Induction and accumulation of PR protein activity during early stages of root colonization by the mycoparasite Trichoderma harzianum strain T-203. Plant Physiol. Biochem. 38:863-873.

Yu, L. M. 1995. Elicitins from Phytophthora and basic resistance in tobacco. Proc. Natl. Acad. Sci. U.S.A. 92:4088-4094.

Zavala-Paramo, G., Chavez-Moctezuma, M. P., Garcia-Pineda, E., Yin, S., Chappell, J., and Lozoya-Gloria, E. 2000. Isolation of an elicitor-stimulated 5-epi-aristolochene synthase gene (gPEAS1) from chili pepper (Capsicum annuum). Physiol. Plantarum 110:410-418.

\section{AUTHOR-RECOMMENDED INTERNET RESOURCE}

GreenGene Bio Tech Inc. database: www.ggbio.com

\section{Erratum}

Some authors' affiliations were identified incorrectly. Corrections were made to the list of authors on April 4, 2011. 